\title{
Localization of mRNAs coding for mitochondrial proteins in the yeast Saccharomyces cerevisiae
}

\author{
NOGA GADIR, ${ }^{1}$ LIORA HAIM-VILMOVSKY, ${ }^{1}$ JUDITH KRAUT-COHEN, and JEFFREY E. GERST ${ }^{2}$ \\ Department of Molecular Genetics, Weizmann Institute of Science, Rehovot 76100, Israel
}

\begin{abstract}
Targeted mRNA localization is a likely determinant of localized protein synthesis. To investigate whether mRNAs encoding mitochondrial proteins (mMPs) localize to mitochondria and, thus, might confer localized protein synthesis and import, we visualized endogenously expressed mMPs in vivo for the first time. We determined the localization of 24 yeast mMPs encoding proteins of the mitochondrial matrix, outer and inner membrane, and intermembrane space and found that many mMPs colocalize with mitochondria in vivo. This supports earlier cell fractionation and microarray-based studies that proposed mMP association with the mitochondrial fraction. Interestingly, a number of mMPs showed a dependency on the mitochondrial Puf3 RNA-binding protein, as well as nonessential proteins of the translocase of the outer membrane (TOM) complex import machinery, for normal colocalization with mitochondria. We examined the specific determinants of ATP2 and OXA1 mRNA localization and found a mutual dependency on the 3' UTR, Puf3, Tom7, and Tom70, but not Tom20, for localization. Tom6 may facilitate the localization of specific mRNAs as $O X A 1$, but not $A T P 2$, mRNA was mislocalized in tom6 $\mathrm{sells.}$ Interestingly, a substantial fraction of $O X A 1$ and $A T P 2$ RNA granules colocalized with the endoplasmic reticulum (ER) and a deletion in MDM10, which mediates mitochondria-ER tethering, resulted in a significant loss of OXA1 mRNA localization with ER. Finally, neither ATP2 nor OXA1 mRNA targeting was affected by a block in translation initiation, indicating that translation may not be essential for mRNA anchoring. Thus, endogenously expressed mRNAs are targeted to the mitochondria in vivo, and multiple factors contribute to $\mathrm{mMP}$ localization.
\end{abstract}

Keywords: Puf3; TOM complex; mRNA; mitochondria; yeast

\section{INTRODUCTION}

A fundamental element of eukaryotic cells is their ability to create different functional membrane-bound compartments containing specific proteins. Protein distribution to these compartments calls for the specific sorting and, possibly, local synthesis of proteins. Mitochondria play a central role in energy conversion, the metabolism of lipids and amino acids, as well as the regulation of apoptosis. While the mitochondrial genome encodes a few proteins, hundreds of mitochondrial proteins are encoded by nuclear genes, translated in the cytoplasm, and imported into mitochondria via a series of complex molecular mechanisms (Kumar et al. 2002; Sickmann et al. 2003; Prokisch et al. 2004; Neupert and Herrmann 2007). The first step of import is mediated

\footnotetext{
${ }^{1}$ These authors contributed equally to this work.

${ }^{2}$ Corresponding author.

E-mail jeffrey.gerst@weizmann.ac.il.

Article published online ahead of print. Article and publication date are at http://www.rnajournal.org/cgi/doi/10.1261/rna.2621111.
}

by the translocase of the outer mitochondrial membrane (TOM) complex, composed of the subunits Tom70, Tom40, Tom22, Tom20, Tom7, Tom6, and Tom5 (Dekker et al. 1998; Neupert and Herrmann 2007). Tom70 and Tom20 are both integral membrane proteins with cytosolic domains that act as receptors for incoming proteins (Moczko et al. 1992; Dekker et al. 1998). Tom70 interacts with hydrophobic precursor proteins, while Tom20 interacts with precursors that have $\mathrm{N}$-terminal mitochondrial targeting signals (MTSs) (Muto et al. 2001).

As most mitochondrial proteins are encoded by nuclear genes and synthesized on what are thought to be cytosolic ribosomes, an important question is whether protein import into mitochondria occurs either post- or cotranslationally. Post-translational import into mitochondria can be achieved using encoded protein-targeting motifs (e.g., MTSs) that become exposed upon translation (Dingwall and Laskey 1991; Neupert and Herrmann 2007). Likewise, different protein-targeting motifs are recognized by the endoplasmic reticulum (ER) to import proteins (Schuldiner et al. 2008) and post-translational import is thought to be independent 
of mRNA localization (Neupert and Herrmann 2007). In contrast, cotranslational import was shown earlier to target secreted or type I integral membrane proteins to the ER and in a manner that involves mRNA localization (Schwartz 2007; Gerst 2008).

A well-studied mitochondrial import mechanism involving the MTS and both the TOM and translocase of the inner membrane (TIM) complexes is thought to be responsible for the import of many mitochondrial proteins. Yet, some evidence supports the idea that import begins before recognition of the MTS by proteins of the TOM complex (Lithgow et al. 1997; Truscott et al. 2003; Pfanner et al. 2004; MacKenzie and Payne 2007). The idea of post-translational protein import into mitochondria originated with two separate studies performed in the 1970s, which demonstrated that mitochondrial proteins synthesized in vitro can undergo import into mitochondria (Harmey et al. 1977; Maccecchini et al. 1979). Later evidence indicated the presence of full-length protein precursors in the cytosol preceding completion of the import process (Wienhues et al. 1991; Schulke et al. 1997). However, studies from Butow and colleagues showed that translationally active ribosomes loaded with mRNAs encoding mitochondrial precursor proteins accumulate on the surface of yeast mitochondria (Kellems et al. 1974, 1975), which could implicate cotranslational translocation as an alternative import process (MacKenzie and Payne 2007). Based on several recent reports, mRNA trafficking and localized translation have been suggested as a potential means for targeting some proteins to mitochondria (Corral-Debrinski et al. 2000; Margeot et al. 2005). For instance, the mitochondrial localization of yeast ATP2 mRNA, which encodes the $\beta$-subunit of the F1ATPase, is essential for proper respiratory function (Margeot et al. 2002, 2005). Moreover, a stretch of $250 \mathrm{nt}$ in the $3^{\prime}$ untranslated region ( $3^{\prime} \mathrm{UTR}$ ) of ATP2 is sufficient to confer mRNA localization and allows for the biogenesis of functional mitochondria (Margeot et al. 2002). Another study identified a 50-nt consensus RNA motif sufficient for targeting ATP2 mRNA to mitochondria (Liu and Liu 2007). In addition, OXA1 mRNA, which encodes an insertase that facilitates the insertion of proteins from the matrix into the inner membrane (Szyrach et al. 2003; Herrmann and Bonnefoy 2004), was found to localize to mitochondria in vivo and in a manner that was also 3' UTR-dependent (Corral-Debrinski et al. 2000; Sylvestre et al. 2003).

Interestingly, approximately 500 mRNAs have been suggested to localize to yeast mitochondria based on using microarrays to identify nuclear-encoded mRNAs that copurify with mitochondria-containing subcellular fractions (Marc et al. 2002; Gonsalvez et al. 2005; Margeot et al. 2005; Saint-Georges et al. 2008). About half of all mMPs are thought to be translated in the vicinity of mitochondria and mRNAs of this class were named mitochondrially localized mRNAs (MLRs) (Marc et al. 2002). This suggested that mitochondrial protein import could be cotranslational and indicated that MLR proteins are mainly of prokaryotic origin, linked to the assembly of core complexes, and are imported principally via the TOM-TIM23 pathway (Garcia et al. 2007). Puf3, an RNA-binding protein (RBP) that belongs to the Pumilio-Fbf (Puf) family and interacts with more than 150 mMPs (Gerber et al. 2004), was recently shown to be involved in the transport of mMPs encoding proteins involved in respiration and translational control within the organelle; and the loss of PUF3 gene expression influenced mRNA association with the mitochondria (SaintGeorges et al. 2008). Finally, the use of general inhibitors of protein translation and mutational analyses show that mMP localization to mitochondria is, at least in part, translationdependent (Saint-Georges et al. 2008; Garcia et al. 2010). Thus, mMP association with mitochondria could occur as a result of cotranslational translocation.

Together, these studies strongly suggest that mRNAs may access the mitochondrial membrane, perhaps to allow for cotranslational protein import. However, these earlier studies relied mainly on subcellular fractionation and transcriptome analyses or plasmid-based mRNA expression and localization systems, rather than examining the localization of endogenously expressed mMPs in vivo. Here, we use a novel gene-tagging system, called m-TAG (Haim et al. 2007; Haim-Vilmovsky and Gerst 2009), which allows for the sustained visualization of endogenous mRNAs in live yeast to localize mMPs. This technique involves the insertion of binding sites (e.g., the MS2 aptamer/loop sequence $[\mathrm{MS} 2 \mathrm{~L}])$ for the bacteriophage MS2 coat protein (MS2-CP) into genes of interest in the yeast genome. Upon the expression of MS2-CP fused with GFP(x3), endogenously expressed mRNAs are visualized in vivo, and $\mathrm{m}$-TAG has been used to localize endogenous ASH1 and SRO7 mRNAs to the bud tip, PEX3 mRNA to the ER, OXA1 mRNA to mitochondria (Haim et al. 2007), and mRNAs encoding peroxisomal proteins (mPPs) to the peroxisome (Zipor et al. 2009).

Here we describe the localization of 24 endogenously expressed mRNAs encoding proteins of the mitochondrial matrix, outer and inner membranes, and intermembrane space. We show that the majority of these mRNAs localize to the vicinity of the mitochondria in vivo, and many demonstrate a partial dependency on Puf3 for their localization. These results largely support earlier findings made using subcellular fractionation and microarray analyses; however, they do suggest that Puf3 is not absolutely essential for $\mathrm{mMP}$ localization and that respiration is not altered in its absence. By using ATP2 and OXA1 as model mMPs, we found that the tom $6 \Delta$, tom $7 \Delta$, tom $20 \Delta$, and tom $70 \Delta$ mutants typically led to $\mathrm{mMP}$ delocalization and indicate a role for TOM complex components in mMP localization. Interestingly, this is likely to be independent of translation initiation, as mutation of the translation initiation codon did not significantly affect mMP localization. In contrast, removal of the 3' UTR strongly altered ATP2 and OXA1 mRNA localization to mitochondria and increased OXA1 mRNA 
mislocalization to nuclear ER. Localization to the nuclear ER increased further when both the $3^{\prime}$ UTR and ATG were removed, indicating that the ER may be a default compartment for mMPs when mitochondrial targeting is affected. Together, these results show that mMPs are targeted to mitochondria in vivo and use a variety of individual factors (e.g., their 3' UTRs, Puf3, and TOM complex components) to ensure proper localization.

\section{RESULTS}

\section{Visualization of endogenous mRNAs encoding mitochondrial proteins}

To localize endogenously expressed mMPs in vivo in yeast, we used m-TAG (Haim et al. 2007; Haim-Vilmovsky and Gerst 2009) to insert the MS2 aptamer sequence between the coding region and 3' UTR of genes encoding proteins of the mitochondria outer (e.g., DNM1, FIS1, MDM10, and OM45) and inner (e.g., ATM1, ATP2, ATP3, ATP10, CAT5, CBS1, MRPL32, OXA1, PHB2, and SDH2) membranes, mitochondrial matrix (e.g., CIT1, SSC1), and intermembrane space (e.g., COX10, CYB2, CYC3) (for a list of all tagged strains, see Table 1). Upon the expression of MS2CP-GFP $(x 3)$ in cells grown on glucose-containing medium, we observed multiple fluorescent RNA granules in cells bearing the MS2L-tagged genes. The granular pattern of labeled RNA is typical for aptamer-tagged mRNAs, and granules containing multiple copies of the message were previously observed (Haim et al. 2007). By using MS2 aptamer-tagged $A T P 2$ as a representative $\mathrm{MMP}$, we found that $A T P 2_{I N T}$ granules had a fluorescent footprint of up to $\sim 200 \mathrm{~nm}$ in size and contained three to six individual mRNAs (average \pm standard deviation $=4.3 \pm 0.8$ mRNAs per granule; $n=10$ granules), as calculated using an integrated 128-mer lac operator GFP-LacI fluorescencequantification method (Haim et al. 2007; Haim-Vilmovsky and Gerst 2009). Thus, multiple copies of mMPs can exist in the same granule, as observed previously for the ASH1 (Haim et al. 2007) and POX1 mRNAs (Zipor et al. 2009).

In some cases, however (see below), we were unable to observe significant numbers of granules and, therefore, grew these cells on medium containing a nonfermentable carbon source (e.g., $2 \%$ glycerol) to induce gene expression. Alternatively, we used MS2-CP fused to four GFP molecules [MS2-CP-GFP(x4)] (Zipor et al. 2009) to localize mMPs that were poorly visualized using MS2-CP-GFP(x3) under any condition. The statistics corresponding to $\mathrm{mMP}$ localization to mitochondria are given in Table 1 and are based on determining the percentage of GFP-labeled RNA granules that overlap directly with RFP-labeled mitochondria in vivo (for additional information, see Materials and Methods).

Out of 24 tagged mMPs, we found that the ATM1, ATP2, ATP10, CYB2, COX10, MDM10, and OXA1 mRNA granules exhibited very high levels of colocalization with mitochondria (e.g., $>80 \%$ ), while the $C B S 1, C Y C 3$, and FIS1 mRNAs demonstrated low levels of colocalization (i.e., $\leq 24 \%$ ) on glucose-containing medium (Fig. 1A; Table 1). The rest of the tagged endogenously expressed mRNAs (e.g., ATP3, ATP10, CAT5, CIT1, COQ4, DNM1, GGC1, IMG1, MRPL32, OM45, PHB2, RSM25, SDH2, and SSC1) showed more moderate levels of colocalization that ranged between $31 \%$ and $76 \%$ on glucose-containing medium (Fig. 1A; Table 1). In the case of the CIT1, DNM1, and MDM10 mRNAs, there were difficulties in observing granules on glucose-containing medium, and, therefore, we grew the cells on glycerol-containing medium and examined mRNA localization to mitochondria. Under these conditions, CIT1, DNM1, and MDM10 mRNA granules were readily observed and showed a moderate-high level of colocalization (i.e., 70\%, 63\%, and 90\%, respectively) (Fig. 1A; Table 1). In contrast, glycerol induction did not increase granule formation for the ACN9, IMG1, and RSM25 mRNAs. Therefore, we used MS2-CP-GFP $(\mathrm{x} 4)$ to localize these mRNAs and now observed fluorescent granules in a high percentage of cells expressing MS2-CP-GFP(x4) on glucose-containing medium. Colocalization for these RNAs with mitochondria was $22 \%, 76 \%$, and $58 \%$, respectively (Table 1$)$. To verify that the GFP(x4) moiety does not alter the outcome of localization, we expressed MS2-CP-GFP(x4) in $A T P 2_{I N T}$ cells as a control. We found that the level of granule colocalization with mitochondria was essentially identical to that observed using MS2-CP-GFP(x3) (i.e., $91 \%$ and $95 \%$ colocalization, respectively) (Table 1).

Overall, seven mMPs had high levels of colocalization with the mitochondria (i.e., $>80 \%$ ), 14 had low-moderate levels of colocalization (i.e., $31 \%-76 \%$ ), and three had very low levels of colocalization (i.e., $\leq 24 \%$ ). The latter set of numbers is close to what we have described as background levels of mRNA colocalization, given the compact nature of yeast cells and a tendency for the fluorescent footprints of labeled large organelles and RNA granules to partially overlap (Zipor et al. 2009). Given the large variability in the extent of mMP colocalization with mitochondria, we examined whether control mRNAs (known to localize elsewhere in the cell) can colocalize with mitochondria. We first examined endogenously expressed MS2L-tagged ASH1 mRNA, which we have shown to localize asymmetrically to the bud tip (Haim et al. 2007), as well as tagged MYO2 mRNA, whose localization was unknown but whose protein localizes to the bud tip like Ash1 protein (Lillie and Brown 1994). We found that tagged ASH1 and MYO2 mRNAs both localized to the bud tip and showed only a very low level of colocalization with mitochondria (e.g., $18 \%$ and $12 \%$, respectively) (Table 1 ). In addition, we examined the localization of USE1 and YIP3 mRNAs, which encode membrane proteins involved Golgi-ER retrograde transport and ER-Golgi anterograde transport, respectively, and are distributed broadly to the ER and Golgi compartments (Otte et al. 2001; Calero and Collins 2002; Dilcher 
TABLE 1. Localization of mRNAs encoding mitochondrial proteins in yeast

\begin{tabular}{|c|c|c|c|c|c|c|c|c|c|c|}
\hline \multirow{2}{*}{$\begin{array}{l}\text { Gene accession } \\
\text { number }\end{array}$} & \multirow[b]{2}{*}{ Gene name } & \multirow[b]{2}{*}{ INT } & \multirow{2}{*}{$\begin{array}{l}\text { Detected } \\
\text { by } \\
\text { CP-GFP(x3) }\end{array}$} & \multirow{2}{*}{$\begin{array}{l}\text { Detected } \\
\text { by } \\
\text { CP-GFP(x4) }\end{array}$} & \multirow{2}{*}{$\begin{array}{l}\text { Puf3 } \\
\text { binding } \\
\text { site }\end{array}$} & \multicolumn{3}{|c|}{$\begin{array}{l}\% \text { of granules } \\
\text { colocalized with } \\
\text { mitochondria }\end{array}$} & \multirow{2}{*}{$\begin{array}{l}\% \text { of granules } \\
\text { colocalized with } \\
\text { peroxisomes }\end{array}$} & \multirow{2}{*}{$\begin{array}{c}\text { Protein } \\
\text { localization }\end{array}$} \\
\hline & & & & & & WT & puf3 $\Delta$ & tom $20 \Delta$ & & \\
\hline YDR511W & ACN9 & + & & + & + & $22 \%$ & $-^{a}$ & - & - & $\mathrm{INT}^{\mathrm{b}}$ \\
\hline YKL185W & ASH1 & + & + & & - & $18 \%$ & - & - & - & Nucleus \\
\hline YMR301C & ATM1 & + & + & & - & $88 \%$ & $84 \%$ & - & $8 \%$ & $\mathrm{IM}^{\mathrm{C}}$ \\
\hline YJR121W & ATP2 & + & + & + & - & $95 \%$ & $56 \%$ & $72 \%$ & $14 \%$ & IM \\
\hline YBR039W & ATP3 & + & + & & - & $68 \%$ & - & - & - & IM \\
\hline YLR393W & ATP10 & + & + & & - & $84 \%$ & - & - & - & IM \\
\hline YOR125C & CAT5 & + & + & & - & $56 \%$ & - & - & - & IM \\
\hline YDL069C & CBS1 & + & + & & - & $24 \%$ & - & - & $13 \%$ & IM \\
\hline YNR001C & CIT1 & + & $+^{\mathrm{e}}$ & & - & $70 \%$ & $70 \%$ & - & $10 \%$ & $M X^{d}$ \\
\hline YPL1172C & $C O \times 10$ & + & + & & + & $90 \%$ & $87 \%$ & - & - & INT \\
\hline YML054C & CYB2 & + & + & & - & $96 \%$ & - & - & - & INT \\
\hline YDR204W & COQ4 & + & + & & - & $58 \%$ & - & $42 \%$ & - & IM \\
\hline YAL039C & CYC3 & + & + & & + & $0 \%$ & - & - & - & INT \\
\hline YLL001W & DNM1 & + & $+^{\mathrm{e}}$ & & - & $63 \%$ & - & - & $3 \%$ & $O M^{f}$ \\
\hline YIL065C & FIS1 & + & + & & - & $24 \%$ & - & - & - & OM \\
\hline YDL198C & GGC1 & + & + & & - & $32 \%$ & - & - & - & IM \\
\hline YCR046C & IMG1 & + & & + & + & $76 \%$ & $38 \%$ & - & - & Ribosomal \\
\hline YAL010C & MDM10 & + & $+^{\mathrm{e}}$ & & - & $90 \%$ & $90 \%$ & - & $2 \%$ & $\mathrm{OM}$ \\
\hline YCR003W & MRPL32 & + & + & & + & $33 \%$ & - & - & - & IM \\
\hline YOR326W & MYO2 & + & + & & - & $12 \%$ & - & - & - & Cytoplasm \\
\hline YIL136W & OM45 & + & + & & - & $54 \%$ & - & - & - & OM \\
\hline YER154W & OXA1 & + & + & & + & $82 \%$ & $42 \%$ & $76 \%$ & - & IM \\
\hline YGR231C & PHB2 & + & + & & - & $31 \%$ & - & - & - & IM \\
\hline YIL093C & RSM25 & + & & + & + & $58 \%$ & $28 \%$ & - & - & Ribosomal \\
\hline YLL041C & $\mathrm{SDH} 2$ & + & + & & - & $37 \%$ & - & - & - & IM \\
\hline YJR045C & SSC1 & + & + & & - & $66 \%$ & - & $36 \%$ & - & $M X$ \\
\hline YGL098W & USE1 & + & + & & - & $28 \%$ & - & - & - & \\
\hline YNL044W & YIP3 & + & + & & - & $32 \%$ & - & - & - & \\
\hline \multicolumn{11}{|c|}{$\begin{array}{l}{ }^{a} \text { Not determined. } \\
\text { b Intermembrane space. } \\
\text { cInner membrane. } \\
{ }^{\mathrm{d}} \text { Matrix. } \\
{ }^{e} \text { Glycerol used to induce gene expression. } \\
\text { f Outer membrane. }\end{array}$} \\
\hline
\end{tabular}

et al. 2003; Geng et al. 2005). We found that the USE1 and YIP3 mRNAs localized primarily with ER peripheral to the nucleus (nuclear ER; nER) (i.e., 52\% colocalization with nER and $26 \%$ colocalization with cER for USE1 [78\% ER total]; and $40 \%$ colocalization with nER and 29\% colocalization with cER for YIP3 [69\% ER total]) (data not shown), but exhibited only low levels of colocalization with mitochondria (e.g., 28\% and 32\%) (Table 1). Given the close proximity between ER and mitochondria (Prinz et al. 2000), this level of colocalization is probably background.

Functional mitochondria are required for yeast to use glycerol as a carbon source. To verify that the MS2 loop sequence inserted between the ORF and 3' UTR does not alter protein function, we examined the ability of the $M S 2 L$ tagged strains to grow on glycerol-containing plates (Fig. 1B). For example, yeast expressing aptamer-tagged ATP2 and $O X A 1 \mathrm{mRNAs}$ grew like wild-type cells, whereas strains lacking functional mitochondrial genes were unable to grow
(Fig. 1B). In addition, no tagged gene encoding a mitochondrial protein showed defects on glucose-containing medium, and, when examined, we found that the $M S 2 L$-tagged ATM1, MDM10, and SDH1 strains grew well on the nonfermentable carbon source (data not shown). Finally, tagged essential genes, such as MYO2, SSC1, and USE1, showed no growth defects on glucose-containing medium (data not shown). Thus, MS2 aptamer insertion into the message does not appear to alter protein function, as was shown previously (Haim et al. 2007; Zipor et al. 2009).

\section{Puf3-dependent and -independent endogenous mRNA localization to the mitochondria}

The Puf3 RBP has been suggested to be involved in the transport of a subset of mMPs to the mitochondrial exterior (Gerber et al. 2004; Saint-Georges et al. 2008). As these studies involved the use of in situ experiments or microarray 


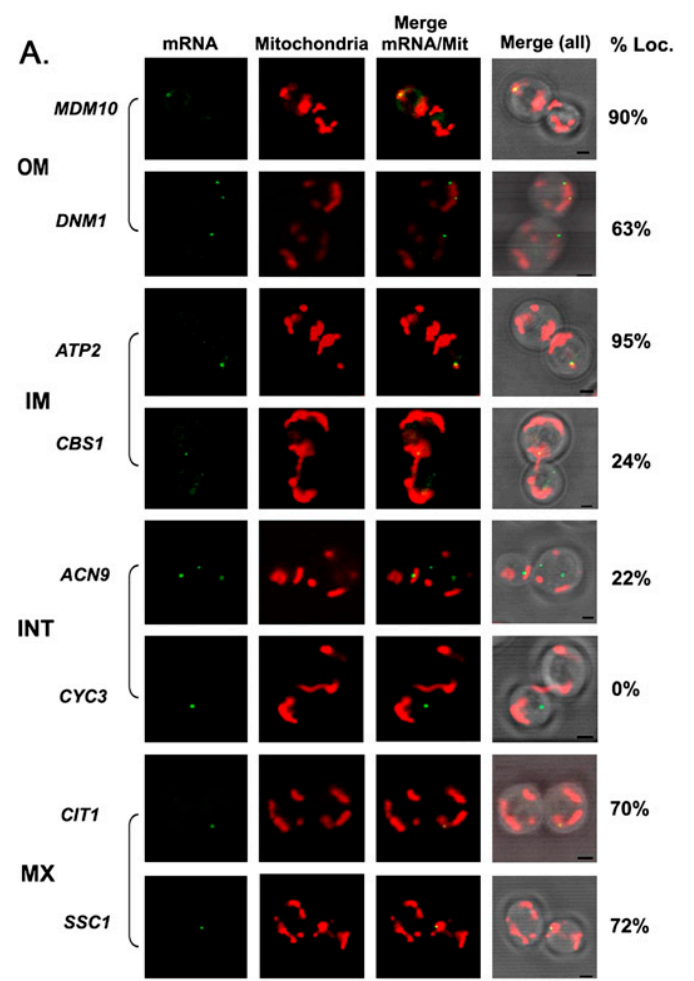

B.
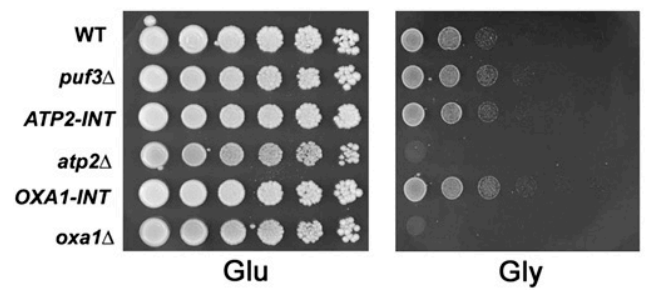

FIGURE 1. Visualization of endogenous mRNAs encoding mitochondrial proteins. $(A) \mathrm{mMP}$ colocalization with mitochondria. Cells bearing the $M S 2 L$ sequence integrated into different ORFs were transformed with plasmids expressing MS2-CP-GFP(x3) and Oxa1RFP (a mitochondrial marker). Cells were grown on liquid synthetic medium containing glucose to mid-log phase at $26^{\circ} \mathrm{C}$ and were induced with the same medium lacking methionine for $1 \mathrm{~h}$ prior to visualization by confocal microscopy. For the CIT1, DNM1, and MDM10 mRNAs, the cells were grown on glycerol (2\%)-containing medium instead of glucose as the carbon source. The percentage of fluorescent RNA granules that colocalized with mitochondria (\% Loc.) is given in \%. (mRNA) Indicates the localization of GFP-labeled RNA granules. (Mitochondria) Indicates the localization of mitochondria labeled with Oxa1-RFP. (Merge mRNA/Mit) Indicates merger of the mitochondrial and mRNA windows. [Merge (all)] Indicates merger of the light (DIC), mitochondrial, and mRNA windows. Scale bar, $2 \mu \mathrm{m}$. (B) Chromosomal MS2 aptamer genetagging does not affect protein function. Wild-type, puf $3 \Delta$, ATP2:: loxP ::MS2L ::ATP2 $2^{3^{\prime} U T R}\left(A T P 2_{I N T}\right)$, atp $2 \Delta$, OXA1 :loxP $:: M S 2 L::$ OXA $1^{3^{\prime} U T R}$, and oxa $1 \Delta$ cells were grown to mid-log phase at $26^{\circ} \mathrm{C}$ on glucose-containing medium, serially diluted, plated onto solid synthetic medium containing either glucose (Glu) or glycerol (Gly) as a carbon source, and grown for $48 \mathrm{~h}$ at $26^{\circ} \mathrm{C}$. Note that functional Oxa1 and Atp2 are necessary for growth on glycerol. analyses, we examined whether the loss of PUF3 expression affects mMP localization to mitochondria in vivo. To examine the dependence on Puf3, we deleted PUF3 in several of our $M S 2 L$-integrated strains by replacement with a kanMX cassette. We found a strong dependence on Puf3 for the colocalization of OXA1, IMG1, and RSM25 mRNAs with mitochondria (e.g., OXA1: $82 \%$ colocalization in wildtype cells vs. $42 \%$ in puf $3 \Delta$ cells; IMG1: $76 \%$ vs. $38 \%$, respectively; and RSM25: $58 \%$ vs. $28 \%$, respectively) (Fig. 2A; Table 1), which is consistent with the fact that all these mRNAs bear a canonical Puf3 binding site (data not shown). We note that despite the apparent decrease in the level of mRNA-mitochondria colocalization seen in puf3s cells, e.g., in the case of OXA1 mRNA, we were still able to visualize a high degree of OXA1 mRNA granule localization to mitochondria in puf3 $\Delta$ cells using time-lapse microscopy overall (Supplemental Movie S1). In this experiment, we found that endogenous OXA1 mRNA granules remained in constant contact with Oxa1-RFP-labeled mitochondria and moved along the length of mitochondrial tubules throughout the experiment $(\sim 1 \mathrm{~h})$, similar to that seen in wild-type cells (data not shown). Thus, while statistically there is a substantial decrease in mRNA-mitochondria colocalization in the overall population, nevertheless, some puf $3 \Delta$ cells show a high degree of colocalization over time. Interestingly, despite the fact that ATP2 mRNA does not bear the Puf3 binding site (Saint-Georges et al. 2008; data not shown), the deletion of PUF3 strongly reduced colocalization, from $95 \%$ to $56 \%$ (Fig. $2 \mathrm{~A}$; Table 1). In the case of ATP2 mRNA, it is possible that it either contains a noncanonical Puf3 binding site or, perhaps, that it is transported as part of a ribonucleoprotein particle that contains transcripts bound to Puf3.

In contrast, the CIT1, MDM10, ATM1, and COX10 mRNAs did not exhibit any change in their colocalization with mitochondria upon PUF3 deletion (Fig. 2B; Table 1), which is consistent with the fact that these mRNAs do not bear a Puf3-binding site. These data confirm the role of Puf3 in the localization of certain mMPs, although in most cases mMP mislocalization was not completely abolished in the absence of Puf3 (Fig. 2; Table 1; Supplemental Movie S1). Moreover, as the deletion of PUF3 does not abolish cell growth on glycerol-containing medium (Fig. 1B), it indicates that this protein is not essential for respiratory growth functions and that mitochondrial proteins involved in this process are likely to be imported into mitochondria in its absence.

\section{Mitochondrial localization requirements for the ATP2 and OXA1 mRNAs}

To determine the requirements for mMP localization, we examined two representative mRNAs, ATP2 and OXA1, using plasmid-based expression (for a summary of the results, see Table 3). ATP2 encodes the $\beta$-subunit of the 

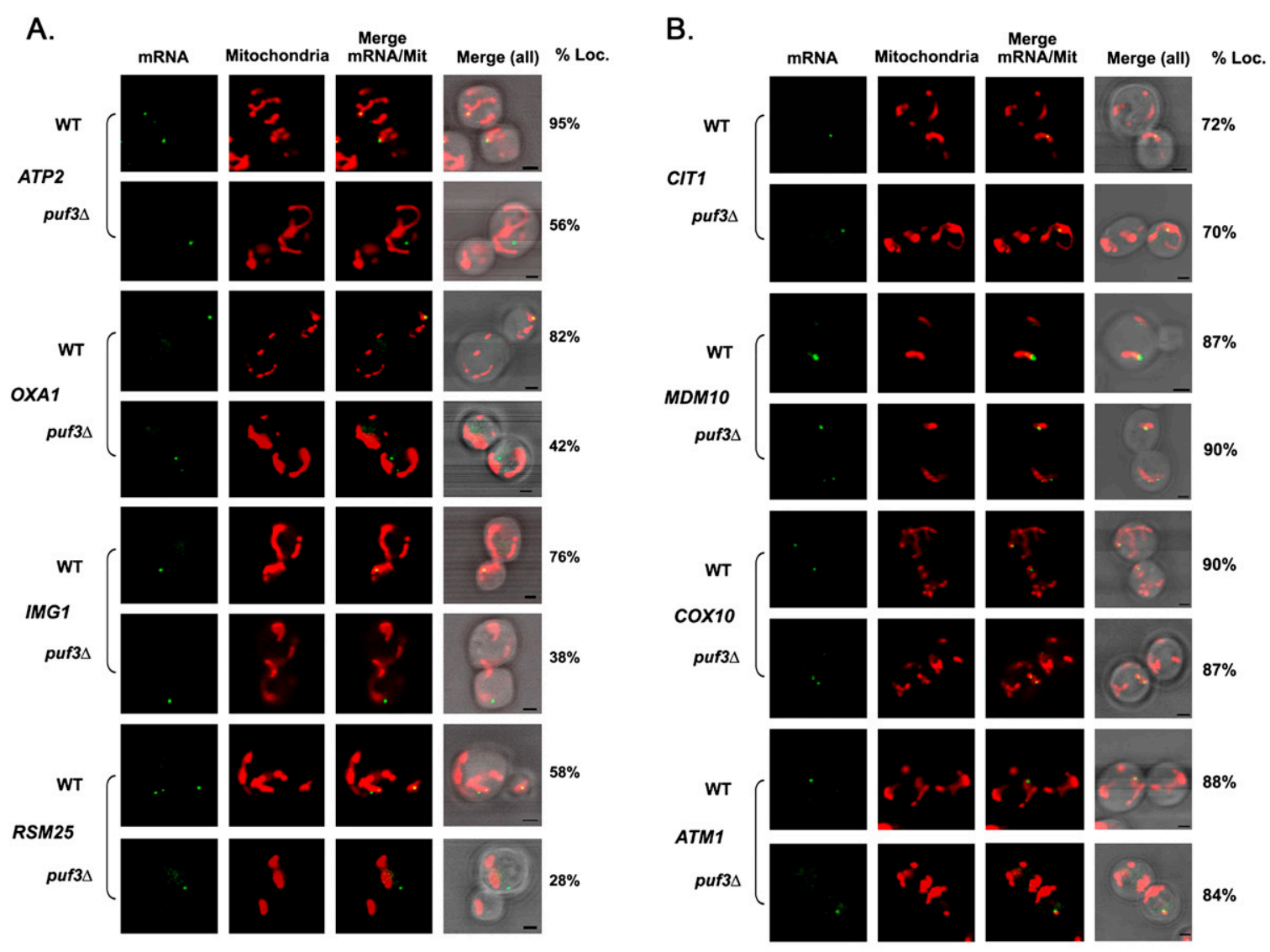

FIGURE 2. Puf3-dependent and -independent mRNA localization to the mitochondria. (A) Puf3-dependent mRNA localization to the mitochondria. Representative confocal images of endogenously expressed MS2L-tagged mMPs in the puf $3 \Delta$ background are shown. Cells cotransformed with plasmids expressing MS2-CP-GFP(x3) to visualize the mRNA and Oxa1-RFP to visualize mitochondria were grown to mid$\log$ phase at $26^{\circ} \mathrm{C}$ on liquid synthetic medium containing glucose and then shifted to the same medium lacking methionine for $1 \mathrm{~h}$. The percentage of RNA granules that colocalize with mitochondria (\% Loc.) is given in \%. (mRNA) Indicates the localization of GFP-labeled RNA granules. (Mitochondria) Indicates the localization of mitochondria labeled with Oxal-RFP. (Merge mRNA/Mit) Indicates merger of the mitochondrial and mRNA windows. [Merge (all)] Indicates the merger between light, mitochondrial, and mRNA windows. Scale bar, $2 \mu \mathrm{m}$. $(B)$ Puf3-independent mRNA localization to the mitochondria. Representative confocal images of endogenously expressed MS2L-tagged mMPs in the puf $3 \Delta$ strain background are shown. Cells were grown to mid-log phase at $26^{\circ} \mathrm{C}$ on liquid synthetic medium and then shifted to medium lacking methionine for $1 \mathrm{~h}$. Cells are labeled as described in $A$.

F1-ATPase, and the localization of its transcript to mitochondria is essential for respiration (Margeot et al. 2002, 2005). Corral-Debrinski and coworkers identified a stretch of $250 \mathrm{nt}$ in the $3^{\prime}$ UTR of ATP2 mRNA that is sufficient for localization and the biogenesis of functional mitochondria (Margeot et al. 2002). Oxa1 is a nuclear-encoded insertase of the inner membrane that facilitates the insertion of both mitochondrial- and nuclear-encoded proteins from the matrix into the inner membrane (Szyrach et al. 2003; Herrmann and Bonnefoy 2004). To monitor ATP2 and OXA1 mRNA localization in vivo, we expressed MS2 looptagged full-length ATP2 and OXA1 mRNAs (including their respective 3 ' UTRs) from single-copy plasmids and under the control of a methionine starvation-inducible promoter. We verified the functionality of these constructs by expressing them in either atp $2 \Delta$ or oxa1s cells and found that they fully complemented the loss of their respective genes (i.e., by restoring growth on a nonfermentable carbon source)
(Supplemental Fig. S1). To determine mRNA localization, we expressed the constructs in wild-type cells along with MS2-CP-GFP(x3) to visualize mRNA and RFP-tagged Oxa1 to visualize mitochondria (Aronov et al. 2007; Haim et al. 2007). Cells were grown on glucose-containing medium and were shifted to the same medium lacking methionine for $1.5 \mathrm{~h}$ to induce expression.

To help determine how ATP2 and OXA1 mRNA localize to mitochondria, we examined colocalization using their full-length mRNAs, mRNAs lacking their 3' UTRs, mRNAs lacking their initial ATG to prevent translation, and mRNAs lacking both their initial ATG and their 3' UTR (for schematic, see Fig. 3A). We found that $70 \%$ of fulllength ATP2 mRNA granules colocalized with RFP-Oxa1labeled mitochondria (Fig. 3B, Table 2), which was only slightly lower than that observed with endogenously expressed ATP2 mRNA (Fig. 1A; Table 1). Interestingly, this level of colocalization was reduced to $36 \%$ when the 
A

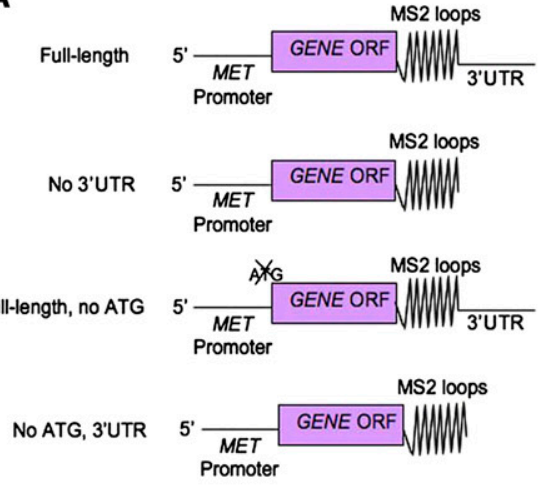

B

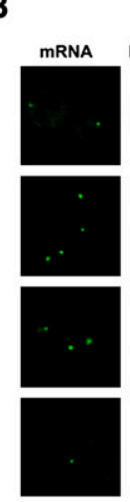

ATP2

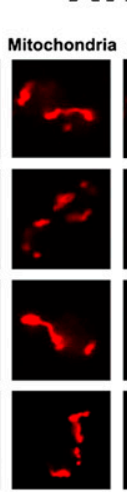

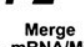

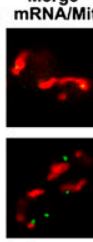

西

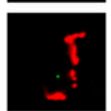

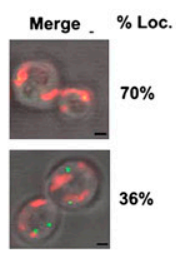
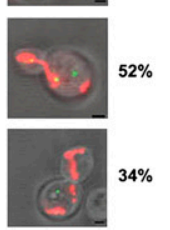

C

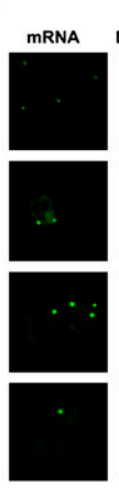

OXA1

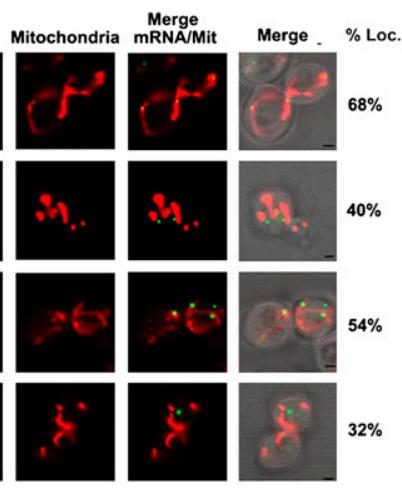

FIGURE 3. Requirements for the colocalization of $A T P 2$ and OXA1 mRNAs with mitochondria. (A) Schematic of the different MS2 aptamertagged ATP2 and OXA1 mRNAs tested. Four different MS2L-tagged ATP2 and OXA1 mRNAs (e.g., native [Full-length]; lacking the 3' UTR [No $3^{\prime} \mathrm{UTR}$; ; bearing a mutated start codon [Full length, no ATG]; or lacking the $3^{\prime}$ UTR and bearing a mutated start codon [no ATG, $\left.3^{\prime} \mathrm{UTR}\right]$ ) were expressed from a single-copy plasmid and under the control of the MET25 methionine starvation-inducible promoter, and examined for localization in wild-type cells by confocal microscopy. (B) ATP2 mRNA colocalization is 3' UTR-dependent. Representative confocal microscopy images of cells transformed with plasmids expressing MS2-CP-GFP(x3) and Oxa1-RFP together with the different MS2L-tagged ATP2 mRNAs are shown. Cells were grown to mid-log phase at $26^{\circ} \mathrm{C}$ on liquid synthetic medium containing glucose and then shifted to medium lacking methionine for $1 \mathrm{~h}$. The percentage of RNA granules that colocalize with mitochondria (\% Loc.) is given in \%. (mRNA) Indicates the localization of GFP-labeled RNA granules. (Mitochondria) Indicates the localization of mitochondria labeled with Oxa1-RFP. (Merge mRNA/Mit) Indicates the merger of the mitochondrial and mRNA windows. (Merge) Indicates the merger between light, mitochondrial, and mRNA windows. Scale bar, $2 \mu \mathrm{m}$. (C) OXA1 mRNA colocalization is 3' UTR-dependent. Representative confocal microscopy images of cells transformed with plasmids expressing MS2-CP-GFP(x3) and Oxa1-RFP together with the different $M S 2 L$-tagged $O X A 1 \mathrm{mRNAs}$. Cells were grown to mid-log phase at $26^{\circ} \mathrm{C}$ on liquid synthetic medium and then shifted to medium lacking methionine for $1 \mathrm{~h}$. Cells are labeled as described in $B$.

3' UTR was removed; to $52 \%$ when the start codon was removed; and to $34 \%$ when both the $3^{\prime}$ UTR and ATG were mutated (Fig. 3B; Table 2). In the case of OXA1 mRNA, we found that $68 \%$ of full-length OXA1 RNA granules colocalized with mitochondria (Fig. 3C; Table 2), which was also somewhat less than the endogenously expressed message (Fig. 1A; Table 1). Removal of the $3^{\prime}$ UTR reduced OXA1 mRNA colocalization with the mitochondria from $68 \%$ to $40 \%$; to $54 \%$ when the start codon was removed; and to $32 \%$ when both mutations were present (Fig. 3C; Table 2). Taken together, the data suggest that the $3^{\prime}$ UTR is necessary for ATP2 and OXA1 mRNA localization to mitochondria (Table 3).

We next examined the localization of ATP2 and OXA1 mRNAs in puf3 4 cells (Fig. 4A; Table 2). We noted reduced levels of colocalization for both full-length messages, as seen previously (Fig. 2A), but that the combination of the three mutations (i.e., puf $3 \Delta, 3^{\prime}$ UTR removal, and translation initiation mutation) led to background levels of mRNA localization to mitochondria (i.e., $28 \%$ for ATP2 and $22 \%$ for OXA1 mRNA) (Fig. 4A; Table 2). This suggests that all three elements contribute to mMP targeting (Table 3).

We next determined to where the ATP2 and OXA1 mRNAs localize when not colocalized with mitochondria. We first examined colocalization with ER and found that $37 \%$ of granules comprising the full-length mRNAs were either associated with or juxtaposed to the ER in wild-type cells (Fig. 4B; Table 2). Interestingly, while the ATP2 mutant lacking the $3^{\prime}$ UTR and initiation codon did not show any greater colocalization with ER, OXA1 mRNA bearing the double mutation exhibited a higher level of colocalization with ER and, specifically, with the nuclear ER. This indicates that OXA1 mRNA may preferentially localize with ER when mistargeted or might require these elements to undergo transport from the ER to mitochondria, if such a pathway operates in $\mathrm{mMP}$ targeting.

To study the possible involvement of mitochondrial membrane potential $(\mathrm{mt} \Delta \Psi)$ in the localization of ATP2 and OXA1 mRNAs, carbonyl cyanide $m$-chlorophenyl hydrazone (CCCP) was added at a concentration known to decrease membrane potential (Martin et al. 1991; Geissler et al. 2000). The localization of OXA1 mRNA granules to the mitochondria was found to decrease from $83 \%$ colocalization to 59\% within $20 \mathrm{~min}$, while that for ATP2 mRNA was lowered from $75 \%$ to $58 \%$, before recovery after $90 \mathrm{~min}$. These data suggest that normal $\mathrm{mt} \Delta \Psi$ is not absolutely necessary for RNA localization, although a recent study showed that treatment with CCCP temporally altered the localization of ATP2-LacZ hybrid gene and ATP4 mRNA (Garcia et al. 2010). It was suggested therein that import processes (i.e., interactions with mitochondrial translocases, like Tom20) might precede mRNA anchoring.

\section{Localization of ATP2 and OXA1 mRNAs in tom6 4 , tom $7 \Delta$, tom20s, and tom $70 \Delta$ cells}

Proteins destined for the different mitochondrial compartments are imported through the outer membrane via the 
TABLE 2. OXA1 and ATP2 mRNA localization to mitochondria and $E R$

\begin{tabular}{|c|c|c|c|c|c|c|c|c|c|}
\hline \multirow[b]{2}{*}{ Gene expressed } & \multicolumn{6}{|c|}{$\%$ of granules colocalized with mitochondria } & \multicolumn{3}{|c|}{$\%$ of granules colocalized with ER } \\
\hline & WT & puf3s & tom $70 \Delta$ & tom6s & tom $7 \Delta$ & $m d m 10 \Delta$ & WT & puf3s & $m d m 10 \Delta$ \\
\hline OXA1 Full length & $68 \%$ & $47 \%$ & $42 \%$ & $22 \%$ & $32 \%$ & $62 \%$ & $37 \%$ & $40 \%$ & $28 \%$ \\
\hline OXA1 No 3' UTR & $40 \%$ & $-^{\mathrm{a}}$ & - & - & - & - & - & - & \\
\hline OXA1 Full length no ATG & $54 \%$ & - & - & - & - & - & - & - & - \\
\hline OXA1 No ATG, 3' UTR & $32 \%$ & $22 \%$ & - & - & - & $30 \%$ & $46 \%$ & $56 \%$ & $24 \%$ \\
\hline ATP2 Full length & $70 \%$ & $53 \%$ & $36 \%$ & $92 \%$ & $42 \%$ & $64 \%$ & $37 \%$ & $38 \%$ & $32 \%$ \\
\hline ATP2 No 3' UTR & $36 \%$ & - & - & - & - & - & - & - & - \\
\hline ATP2 Full length no ATG & $52 \%$ & - & - & - & - & - & - & - & - \\
\hline ATP2 No ATG, 3' UTR & $34 \%$ & $28 \%$ & - & - & - & $32 \%$ & $28 \%$ & $22 \%$ & $27 \%$ \\
\hline
\end{tabular}

TOM complex. Tom70 and Tom20 are both nonessential integral membrane proteins with cytosolic domains that act as receptors for nuclear-encoded mitochondrial proteins. Tom70 interacts with hydrophobic precursor proteins, while Tom20 interacts with precursor proteins that have $\mathrm{N}$-terminal mitochondrial targeting signals (Muto et al. 2001; Wu and Sha 2006). Tom 20 was recently shown to have a role in the association of some mMPs with mitochondria (Eliyahu et al. 2010), suggesting a potential role for localized translation in mitochondrial protein import. Tom 20 is proposed to interact with the MTS of translating proteins, but cells lacking TOM20 are viable, and an MTS-tagged GFP is not fully excluded from the mitochondria in tom $20 \Delta$ cells. This indicates that the MTS is probably recognized by additional components. Tom 40 and the three small (50-70 amino acid) proteins: Tom5, Tom6, and Tom 7 comprise the membrane pore for protein translocation (Dekker et al. 1998). Both Tom6 and Tom7 are anchored in the outer membrane via their $\mathrm{C}$ terminals and appear to be involved in assembly of the TOM complex and its stability (Dekker et al. 1998). Tom7 is not involved in the recognition of the MTS, and the deletion of either TOM6 or TOM7 yields only very minor growth defects on nonfermentable medium (Honlinger et al. 1996). In contrast, the tom $6 \Delta$ tom $7 \Delta$ double mutant has strong growth defects on fermentable/nonfermentable medium at elevated temperatures, while the tom $7 \Delta$ tom $20 \Delta$ mutant is inviable altogether (Honlinger et al. 1996).

To examine whether mutations in the TOM genes affect mRNA localization, we expressed ATP2 and OXA1 bearing the MS2 loops and 3' UTR, as described above, along with RFP-OXA1 and MS2-CP-GFP(x3) in the tom $70 \Delta$, tom $6 \Delta$, and tom $7 \Delta$ mutants. The deletion of TOM70 significantly reduced ATP2 and OXA1 mRNA granule colocalization with mitochondria from $70 \%$ to $36 \%$ and from $68 \%$ to $42 \%$, respectively (Fig. 5A; Table 2). Similar results were obtained for ATP2 and OXA1 in tom $7 \Delta$ mutants (e.g., from $70 \%$ to $42 \%$ and from $68 \%$ to $32 \%$, respectively). Interestingly, while the deletion of TOM6 had no effect on ATP2 mRNA localization, it greatly altered OXA1 mRNA granule colocalization with mitochondria (e.g., from $68 \%$ to $22 \%$ ). Thus, Tom6 appears required for the localization of specific mRNAs with mitochondria (Tables 2, 3).

To examine the dependence of mMP localization on Tom20, we deleted TOM20 in several of our MS2L-integrated strains. As seen in Figure 5B, the TOM20 deletion had no significant effect on ATP2 and OXA1 mRNA localization to mitochondria (e.g., $72 \%$ and $76 \%$ colocalization, respectively). In contrast, the mitochondrial localization of SSC1 and COQ4 mRNAs was substantially decreased (e.g., from $66 \%$ to $36 \%$ and $58 \%$ to $42 \%$, respectively). These data are consistent with the observations of Eliyahu et al. (2010), who suggested that some, but not all, mRNAs have a lower association with mitochondria in the absence of TOM20. The overall requirements for OXA1 and ATP2 mRNA localization to mitochondria are summarized in Table 3.

\section{Localization of mMPs to peroxisomes}

Evidence for cargo-selective transport between the mitochondria and peroxisome has been described (Neuspiel et al. 2008), indicating that these organelles may be in close contact, as they are with the ER in yeast (Prinz et al. 2000; Hoepfner et al. 2005; Tabak et al. 2008). Therefore, we examined the localization of endogenously expressed ATP2, CIT1, MDM10, DNM1, CBS1, and ATM1 mRNAs in cells expressing PTS1RFP, a peroxisome marker, and found that only a very low percentage of RNA granules colocalized with RFP-labeled peroxisomes (Fig. 6). Moreover, the "colocalized" mMPs

TABLE 3. OXA1 and ATP2 mRNA requirements for localization

\begin{tabular}{lcccccccc}
\hline & \multicolumn{7}{c}{ Requirement for localization } \\
\cline { 2 - 7 } mRNA & 3' UTR & ATG & Puf3 & Tom70 & Tom6 & Tom7 & Mdm10 \\
\hline OXA1 & +++ & ++ & ++ & ++ & +++ & +++ & - \\
ATP2 & +++ & ++ & ++ & +++ & - & ++ & - \\
\hline
\end{tabular}


appeared juxtaposed to peroxisomes, rather than appearing to associate directly with the organelle.

\section{Localization of ATP2 and OXA1 mRNAs in $\mathrm{mdm} 10 \mathrm{~s}$ cells}

For mMPs like $O X A 1$, we observed enhanced localization to the ER under certain conditions (Table 1). In yeast, mitochondria are physically associated/tethered with ER, and this interaction involves the Mmm1/Mdm10/Mdm12/ Mdm34-containing ER-mitochondria encounter structure (ERMES) (Kornmann et al. 2009). Therefore, such associations might yield an inaccurate estimation of organellespecific mMP localization, especially given the large fluorescent footprint seen using MS2-CP-GFP(x3).

To address whether mMPs can localize to the ER, we examined the localization of either full-length or mutated $O X A 1$ and ATP2 mRNAs missing their translation initiation codons and respective $3^{\prime}$ UTRs in cells lacking MDM10, which is a mitochondrial outer membrane component involved in the sorting and assembly machinery (SAM) and interacts with ER-anchored Mmm1 to form a molecular bridge that facilitates interorganellar contract (Kornmann et al. 2009). We examined mMP localization in $m d m 10 \Delta$ cells and observed a small decrease in the level of ER localization for both full-length OXA1 and ATP2 mRNAs (i.e., $37 \%$ in wild-type cells vs. $28 \%$ and $32 \%$ in $m d m 10 \Delta$ cells, respectively) (Tables 2,3 ). In contrast, the ER localization of mutant OXA1 mRNA was significantly decreased (i.e., from $46 \%$ in wild-type cells to $24 \%$ in $m d m 10 \Delta$ cells). These results are indicative of a potential involvement for Mdm10 in the association of certain mRNAs with the ER. In contrast, we did not see any necessity for Mdm10 in MMP localization to the mitochondria (Tables 2, 3).

\section{DISCUSSION}

Despite widespread acceptance of mRNA targeting to the ER (Gerst 2008; Kraut-Cohen and Gerst 2010), less support is given to the idea of mRNA targeting to mitochondria. This is primarily because earlier studies revealed the possibility of post-translational import of proteins into isolated mitochondria (Harmey et al. 1977; Maccecchini et al. 1979; Neupert and Herrmann 2007), a mechanism that would not necessitate mRNA localization to mitochondrial membranes. Moreover, the detection of fulllength mitochondrial precursor proteins in the cytosol (Wienhues et al. 1991; Schulke et al. 1997) might also preclude cotranslational import. In contrast, other early studies showed that mRNAs encoding mitochondrial precursor proteins and translationally active ribosomes associate with yeast mitochondria (Kellems et al. 1974, 1975), while recent works (e.g., Margeot et al. 2002; Garcia et al. 2007) used fluorescence microscopy to show that certain mRNAs target to mitochondria. In addition, cell fraction- ation and microarray analyses demonstrated that more than 500 mRNAs are associated with and/or translated on crude mitochondrial fractions (Marc et al. 2002; Saint-Georges
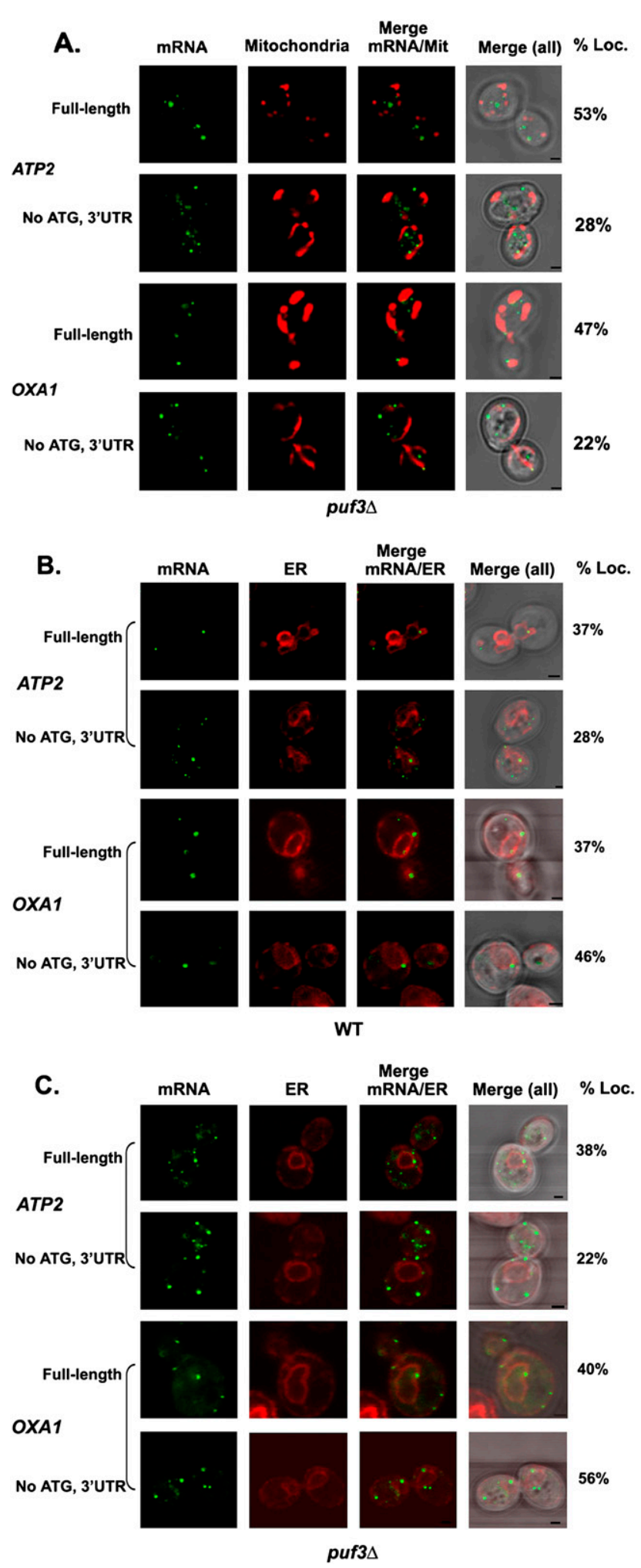

FIGURE 4. (Legend on next page) 
et al. 2008). This is further supported by the demonstration that Puf3 localizes to mitochondria and binds to more than 150 mRNAs encoding mitochondrial proteins (Gerber et al. 2004). Finally, MTS sequences have been shown to alter the steady-state distribution of mitochondrial proteins between the mitochondria and the cytosol (Karniely and Pines 2005; Regev-Rudzki et al. 2008), which might explain why fulllength precursors are found in the cytosol. Although the results supporting the possibility of either post-translational or cotranslational protein import still need to be reconciled, there exists a large body of evidence for the localization of mRNAs to mitochondria.

Since mRNAs are enriched on mitochondrial membranes and as site-specific translation might facilitate the import of mitochondrial proteins into mitochondria, we used our genome-tagging method for localizing endogenously expressed mRNAs in vivo to verify that mMPs are targeted to mitochondria. This study was important not only to help validate previous cell fractionation/transcriptome analyses, but also as a stepping stone to using mRNA affinity purification techniques to identify RBPs and other elements involved in mMP localization (Slobodin and Gerst 2010). Out of the 24 endogenously expressed mMPs examined ( $\sim 4 \%$ of nuclear-encoded mitochondrial genes), at least 17 appeared to show colocalization with mitochondria (Fig. 1A; Table 1). Seven mMPs showed a very high level of colocalization $(>80 \%) ; 10 \mathrm{mMPs}$ showed more

FIGURE 4. Localization of ATP2 and OXA1 mRNAs in puf $3 \Delta$ cells. (A) Localization of ATP2 and OXA1 mRNAs to the mitochondria depends on Puf3, their 3' UTRs, and translation initiation. Representative confocal microscopy images of puf $3 \Delta$ cells transformed with plasmids expressing MS2-CP-GFP(x3) and Oxa1-RFP together with either full-length (Full-length) or mutant (No ATG, 3'UTR) MS2Ltagged ATP2 and OXA1 mRNAs are shown. Cells were grown to mid$\log$ phase at $26^{\circ} \mathrm{C}$ on liquid synthetic medium containing glucose and then shifted to medium lacking methionine for $1 \mathrm{~h}$. The percentage of fluorescent RNA granules that colocalize with mitochondria (\% Loc.) is given in \%. (mRNA) Indicates the localization of GFP-labeled RNA granules. (Mitochondria) Indicates the localization of mitochondria labeled with Oxa1-RFP. (Merge mRNA/Mit) Indicates merger of the mitochondrial and mRNA windows. [Merge (all)] Indicates merger of the light, mitochondrial, and mRNA windows. Scale bar, $2 \mu \mathrm{m}$. (B) Localization of ATP2 and OXA1 mRNAs to the ER in wild-type cells. Representative confocal microscopy images of cells transformed with plasmids expressing MS2-CP-GFP(x3) and Sec63-RFP, as an ER marker, together with the same $M S 2 L$-tagged ATP2 and OXA1 mRNAs as in $A$ are shown. The percentage of RNA granules that colocalize with ER (\% Loc.) is given in \%. (mRNA) Indicates the localization of GFP-labeled RNA granules. (ER) Indicates the localization of ER labeled with Sec63-RFP. (Merge mRNA/ER) Indicates merger of the ER and mRNA windows. [Merge (all)] Indicates the merger between light, ER, and mRNA windows. Scale bar, $1 \mu \mathrm{m} .(C)$ OXA1 mRNA colocalization with ER is enhanced upon the removal of the 3' UTR and start codon. Representative confocal microscopy images of puf $3 \Delta$ cells transformed with plasmids expressing MS2-CPGFP(x3) and Sec63-RFP, together with the same MS2L-tagged ATP2 and OXA1 mRNAs as in $A$ are shown. Cells were grown to mid-log phase at $26^{\circ} \mathrm{C}$ on liquid synthetic medium containing glucose and then shifted to medium lacking methionine for $1 \mathrm{~h}$. Cells are described as in $B$. moderate levels of colocalization $(\sim 40 \%-80 \%)$; and seven mMPs had very low levels of colocalization $(<33 \%)$. The low levels of colocalization seen with the ACN9, CBS1, CYC3, FIS1, GGC1, MRPL32, and PHB2 mRNAs are likely to represent background levels of localization, given that mRNAs encoding secreted/membrane proteins (e.g., USE1 and YIP1) also showed $\sim 30 \%$ colocalization with mitochondria. Alternatively, it may be that certain mMPs have very short residency times on mitochondria, hence the low statistical values for colocalization, as was suggested for certain mRNAs encoding peroxisomal proteins (Zipor et al. 2009). As seen with other tagged RNAs (Aronov et al. 2007; Haim et al. 2007; Zipor et al. 2009), mMPs formed distinct granules that localized transiently to areas on mitochondria, but did not cover the surface of the organelle (Figs. 1, 2; Supplemental Movie S1). Since transcript number for any given mMP is probably low (typically less than 10 copies/cell), it may indicate that translation-translocation of a mitochondrial protein is spatially restricted on the mitochondrial membrane at any given moment. Thus, labeling of the entire mitochondria with a given protein might result from either postimport diffusion within the organelle or, possibly, due to translation-translocation at defined sites on the membrane as a function of time.

As Puf3 binds mMPs and plays a role in their enrichment on mitochondria, we examined whether the deletion of PUF3 affects mMP association with mitochondria in vivo. We found that certain mMPs (e.g., ATP2, IMG1, OXA1, RSM25) showed lower levels of colocalization upon the disruption of PUF3, whereas others (e.g., ATM1, CIT1, COX10, MDM10) were unaffected (Fig. 2). This matches earlier data (Saint-Georges et al. 2008); however, we note that ATP2 mRNA, which does not contain a canonical Puf3-binding site and whose enrichment on mitochondrial membranes was not thought to be Puf3-dependent (SaintGeorges et al. 2008), was delocalized to a large degree in puf3 $\Delta$ cells (Fig. 2; Table 1). This suggests that either Puf3 recognizes additional RNA sequence elements or that mRNAs lacking Puf3-binding sites can be packaged into Puf3-trafficked RNP particles. How packaging occurs and whether it is sequence-dependent (i.e., via RNA-RNA interactions) or protein-dependent, or both, can only be a source of speculation at this juncture. What is of interest is that despite the increase in the delocalization of certain mMPs in puf3 $\Delta$ cells (Fig. 2; Table 1; Gerber et al. 2004; Saint-Georges et al. 2008), mMP localization is not completely blocked, and puf3 $\Delta$ cells are able to grow well on glycerol-containing medium, suggesting that the biochemical pathways involved in respiration are intact and functional. Thus, Puf3 is not an essential factor for mitochondrial biogenesis and function, and one possibility is that Puf3 regulates the extent of $\mathrm{mMP}$ residency (or turnover) on the mitochondrial surface.

Since Puf3 is not required for mMP localization and mitochondrial function, other elements are likely to be 


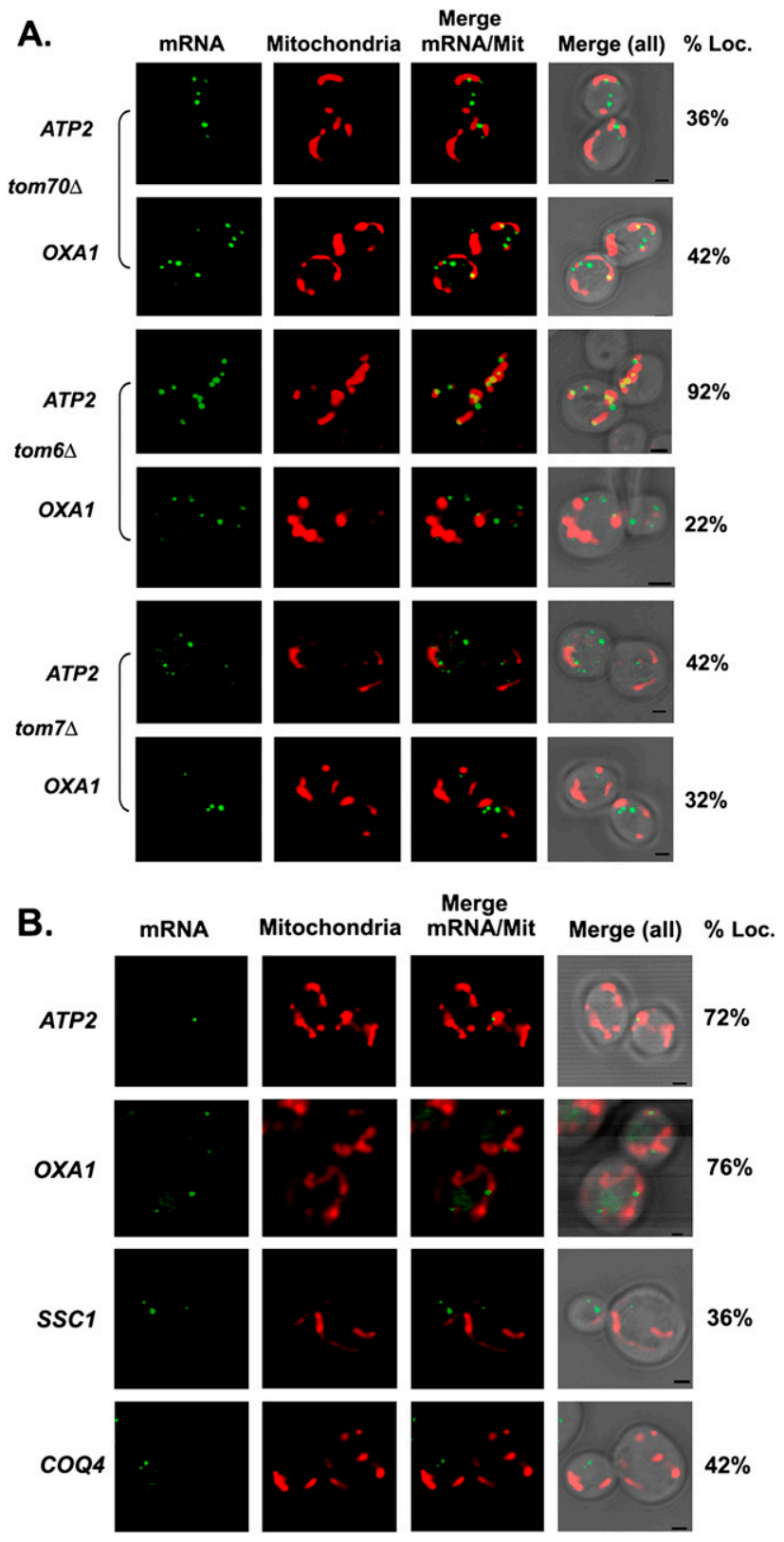

FIGURE 5. Localization of $A T P 2$ and OXA1 mRNAs in TOM complex deletion mutants. (A) Localization of ATP2 and OXA1 mRNAs in the tom $70 \Delta$, tom $6 \Delta$, and tom $7 \Delta$ mutants. Representative confocal microscopy images of the tom $70 \Delta$, tom $6 \Delta$, and tom $7 \Delta$ strains expressing MS2-CP-GFP(x3), Oxa1-RFP, and the MS2L-tagged fulllength $A T P 2$ and OXA1 mRNAs in tom $70 \Delta$, tom $6 \Delta$, and tom $7 \Delta$ are shown. Cells were grown to mid-log phase at $26^{\circ} \mathrm{C}$ on liquid synthetic medium containing glucose and then shifted to medium lacking methionine for $1 \mathrm{~h}$. The percentage of fluorescent RNA granules that colocalize with mitochondria (\% Loc.) is given in \%. (mRNA) Indicates the localization of GFP-labeled RNA granules. (Mitochondria) Indicates the localization of mitochondria labeled with Oxa1RFP. (Merge mRNA/Mit) Indicates merger of the mitochondrial and mRNA windows. [Merge (all)] Indicates merger of the light, mitochondrial, and mRNA windows. Scale bar, $2 \mu \mathrm{m}$. (B) Localization of endogenously expressed mMPs in tom $20 \Delta$ cells. Representative confocal images of endogenously expressed MS2L-tagged mMPs (as listed) in cells lacking TOM20 are shown. Cells were grown and are described as in $A$. involved. To test the involvement of translation, the $3^{\prime}$ UTR, and nonessential TOM complex components, we created plasmid-based expression systems for the ATP2 and OXA1 mRNAs for use in mutational analysis or expression in tom $\Delta$ strains (Figs. 3, 4, 5A; Tables 2, 3). We found that $3^{\prime}$-UTR removal (which removes the Puf3binding site in OXA1) resulted in significant mRNA delocalization from mitochondria, whereas alteration of the translation initiation codon (which is required for MTS expression) had a much lesser effect (Fig. 3B,C). Thus, elements in the $3^{\prime}$ UTR (in conjunction with the Puf3 site) appear critical for ATP2 and OXA1 mRNA localization, as previously suggested (Margeot et al. 2002; Sylvestre et al. 2003). Importantly, the significant contribution of the $3^{\prime}$ UTR to mMP localization implies that localized translation may be important for protein import into mitochondria.

As ATP2 and OXA1 mRNA targeting to the mitochondria was not strongly affected by mutation of the translation initiation codon (Fig. 3; Table 2), it indicates that MTS/protein translation is not obligatory for mMP delivery and localization to mitochondria. This contrasts with PEX14 mRNA, whose localization to peroxisomes was dependent primarily on translational control rather than the 3' UTR (Zipor et al. 2009). Our result also fits with earlier results suggesting that deletion of the Oxa1 $\mathrm{N}$ terminus (i.e., MTS) does not affect OXA1 mRNA localization (Sylvestre et al. 2003). Thus, it would appear that translational control is not essential for localizing the mRNAs we examined to the mitochondria (Table 2). Moreover, it may imply that cotranslational translocation is not important for the import of these proteins. That said, a recent study (Garcia et al. 2010) performed using plasmidexpressed hybrid ATP2-lacZ mRNAs and in situ hybridization suggested that MTS translation, as well as mitochondrial membrane potential, may play a role in mRNA association with mitochondria. However, the 3' UTR of ATP2, which we have found to be critical for targeting to mitochondria (Fig. 3 ), was not present in these experiments. Moreover, we could not demonstrate a large inhibition in mRNA localization using an inhibitor of $\mathrm{mt} \Delta \Psi$. Perhaps MTS translationtranslocation becomes an important factor in mRNA localization only when normal mRNA targeting information is removed. Thus, it would seem likely that integral membrane components of the mitochondria play a role in the association and retention of translating mRNAs on the mitochondrial membrane, rather than in mRNA targeting per se.

Correspondingly, we observed a case-specific dependence for TOM complex components in mMP localization. While Tom 20 is not required for the localization of the ATP2 and OXA1 mRNAs, it is, however, required for normal SSC1 and COQ4 mRNA localization (Fig. 5B). In contrast, Tom70 is required for the mitochondrial localization of the ATP2 and OXA1 mRNAs (Fig. 5A; Tables 2, 3 ), suggesting that the various TOM components interact 


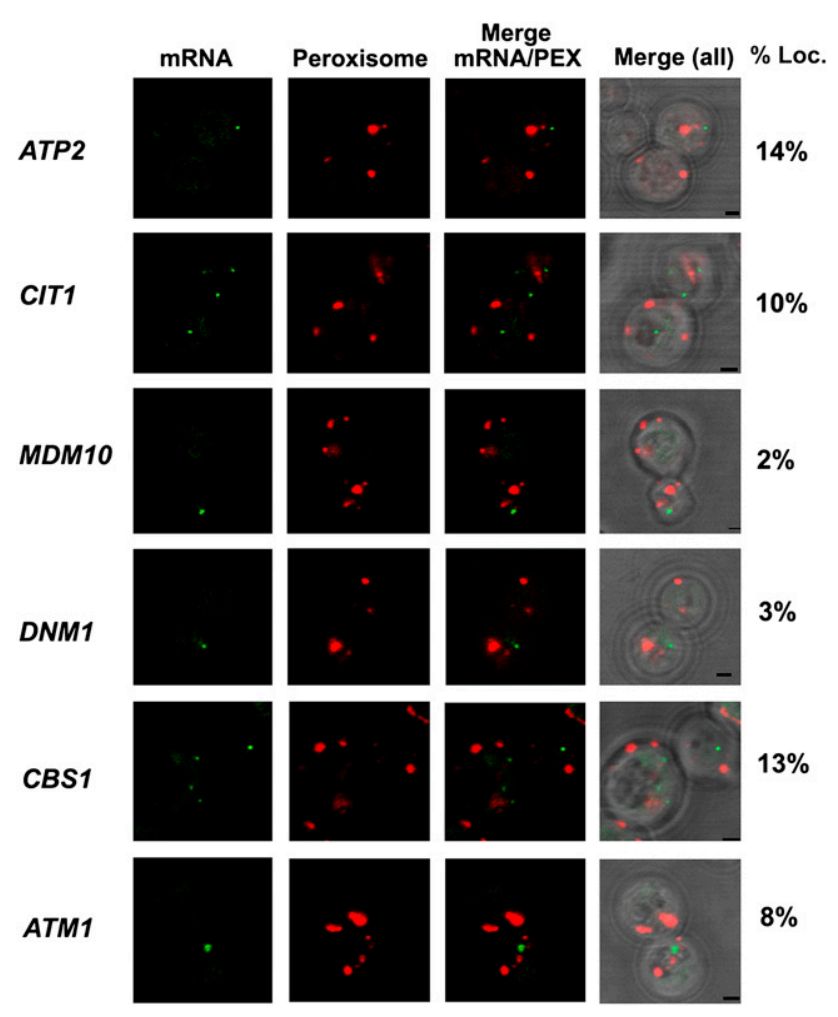

FIGURE 6. mMPs do not localize to peroxisomes. Representative confocal microscopy images of endogenously expressed MS $2 L$-tagged mMPs (as listed) in cells transformed with plasmids expressing MS2CP-GFP(x3) and RFP-PTS1 (a peroxisomal marker). Cells were grown to mid-log phase on liquid selective medium containing glucose at $26^{\circ} \mathrm{C}$ and were induced with the same medium lacking methionine for $1 \mathrm{~h}$ prior to visualization. The percentage of GFPlabeled granules that colocalize with peroxisomes is given in percent (\%). (mRNA) Indicates the localization of GFP-labeled RNA granules. (Peroxisome) Indicates the localization of peroxisomes labeled with RFP-PTS1. (Merge mRNA/PEX) Indicates merger of the peroxisome and mRNA windows. [Merge (all)] Indicates merger of the light, peroxisome, and mRNA windows. Scale bar, $2 \mu \mathrm{m}$.

with different RNAs and, perhaps, different RNP particles. This idea is supported by the demonstration that Tom6 is required for OXA1 mRNA, but not ATP2 mRNA, colocalization with mitochondria (Fig. 5A). Thus, nonessential components of the import machinery could play very specific roles in mMP targeting and protein import. Moreover, when considered together with the combinatorial effects on mMP localization observed on $3^{\prime}$-UTR removal, ATG mutation, or the deletion of PUF3, the differential nature of the results obtained with the tom $\Delta$ mutants implies that there are likely to be parallel paths for mMP delivery and association with mitochondria.

The question of where mMPs go when they are delocalized from mitochondria has not been heretofore addressed. We found that OXA1 mRNA localization to the ER was significant in the absence of Puf3 (e.g., 40\%) and elevated (e.g., 56\% colocalization with ER) when expressed without its $3^{\prime}$ UTR and ATG in puf3 $\Delta$ cells (Fig. 4C; Table
1). While it is unclear how mMPs target to (or associate with) the ER, mRNAs like OXA1 may use nonessential components of the ERMES complex (e.g., Mdm10) for ER attachment (Tables 1,2). Recent work from our laboratory demonstrated that factors involved in protein trafficking to the ER (e.g., Sec $27 / \beta^{\prime} C O P$ ) bind to OXA1 mRNA and facilitate its association with mitochondria (Slobodin and Gerst 2010). Thus, some mMPs may be targeted to ERMES/SAM-marked intermembrane contact sites, perhaps to facilitate protein import into the mitochondria at these foci. That said, we note that there is a general propensity for many mRNAs to associate directly with ER membranes, as was shown by us using fluorescence microscopy and subcellular fractionation studies (Aronov et al. 2007; Haim et al. 2007; Zipor et al. 2009), as well as by the group of Nicchitta and colleagues using subcellular fractionation and microarray analyses (for review, see Gerst 2008). Moreover, mRNAs encoding cytosolic or secreted/membrane proteins target to the ER even in the absence of translation (Kraut-Cohen and Gerst 2010). In contrast, while mMPs colocalize much more strongly with mitochondria than ER, we cannot preclude the possibility that they are trafficked to ER membranes and then to mitochondria. Based on our results, it would seem likely that $\mathrm{mMP}$ association with the ER occurs in the absence of bona fide mMP targeting factors (e.g., Puf3, 3' UTR, MTS sequences, etc.) as part of a default localization pathway. In any case, it is crucial to determine the mechanism by which mMPs undergo trafficking and anchoring, and ongoing studies should aim at distinguishing how mRNA localization to the mitochondria or ER affects subsequent protein localization. Alterations in mMP trafficking could result in an altered localization pattern for mitochondrial proteins and, thus, profoundly affect cellular physiology.

\section{MATERIALS AND METHODS}

\section{Yeast strains, growth conditions, and mRNA imaging}

Yeast strains used in this study are listed in Supplemental Table S1. Yeast were grown to mid-log phase in standard rich growth medium containing either $2 \%$ glucose (YPD) or $3 \%$ glycerol (YPG), or synthetic medium containing glucose (e.g., synthetic complete $[\mathrm{SC}]$ and SC-drop-out medium lacking an amino acid or nucleotide base) or glycerol. For growth tests on glycerol-containing solid medium (YPG; 3\% [v/v] glycerol, 1\% [w/v] Yeast Extract, $2 \%[\mathrm{w} / \mathrm{v}]$ peptone; and $2 \%[\mathrm{w} / \mathrm{v}]$ agar), yeast were grown to mid-log phase, normalized for absorbance at $\mathrm{OD}_{600}$, serially diluted (i.e., $\sim 8 \times 10^{5}$ cells in undiluted sample; followed by 1:10 dilutions), and plated by drops onto solid medium containing glycerol. SC media was prepared as described in Haim-Vilmovsky and Gerst (2009). For treatment with CCCP, yeast were grown to mid-log phase in YPD, normalized for absorbance at $\mathrm{OD}_{600}$, and then shifted to the same medium containing $20 \mu \mathrm{M}$ CCCP for variable exposure periods of up to $2 \mathrm{~h}$. 
For fluorescence microscopy, the induction of mitochondria was performed in the $C I T 1_{I N T}, D N M 1_{I N T}$, and $M D M 10_{I N T}$ strains by growing the cells in liquid synthetic medium containing $3 \%$ glycerol for $4 \mathrm{~h}$, and then shifting to the same medium lacking methionine for $1.5 \mathrm{~h}$ at $26^{\circ} \mathrm{C}$. For the induction of MS2-CP fused to GFP [MS2-CP GFP(x3)], all strains were shifted to medium lacking methionine for $1.5 \mathrm{~h}$ at $26^{\circ} \mathrm{C}$, collected, fixed in a solution containing $4 \%(\mathrm{w} / \mathrm{v})$ paraformaldehyde and $4 \%(\mathrm{w} / \mathrm{v})$ sucrose, and taken directly for imaging by confocal microscopy. Representative images were taken using a Zeiss LSM510 Meta confocal microscope and a PLANApo $100 \times /$ oil objective. The following wavelengths were used: for GFP, excitation at $480 \mathrm{~nm}$ and emission at $530 \mathrm{~nm}$; for monomeric RFP, excitation at $545 \mathrm{~nm}$ and emission at 560 to $580 \mathrm{~nm}$. Colocalization of an MS2L-tagged mRNA with a given organelle (i.e., ER, mitochondria, peroxisome) was determined using fluorescence microscopy. Labels included Sec63RFP (ER), RFP-PTS1 (peroxisome), and Oxa1-RFP (mitochondria). For every $M S 2 L$-integrated strain, we scored the localization of 100 GFP-labeled RNA granules (typically involving 50-100 cells). Numbers corresponding to the percentage of granules for any given mRNA that colocalized with mitochondria, ER, or peroxisomes are given in Tables 1 and 2 .

\section{Plasmids and DNA manipulation}

Plasmid pCP-GFP, which expresses MS2-CP fused to GFP, was provided by K. Bloom (University of North Carolina, Chapel Hill, NC). Plasmid pSL1180, which bears 12 loops of the viral MS2-CP binding site, was provided by R. Singer (Albert Einstein College of Medicine, Bronx, NY). Plasmid pSM1960, which expresses Sec63RFP, was provided by S. Michaelis (Johns Hopkins, Baltimore, $\mathrm{MD})$. Plasmid pSH47, which expresses Cre recombinase from a galactose-inducible promoter, was obtained from Euroscarf. Plasmid pLOXHIS5MS2L was used to generate integration constructs by PCR, as described (Haim et al. 2007). The PCR fragments were transformed into yeast and selected for using the m-TAG gene-tagging procedure, as described (Haim et al. 2007; HaimVilmovsky and Gerst 2009). Plasmid pMS2CPGFP(x3), which expresses MS2-CP-GFP(x3), was previously described (Haim et al. 2007). Plasmid pMS2CPGFP(x4), which expresses MS2-CPGFP(x4), was previously described (Zipor et al. 2009). Plasmids expressing either MS2L-tagged ATP2 or OXA1 were created using a modified pUG36 plasmid, pUG36w/oGFP, lacking both the GFP gene (removed using XbaI and religated). Next, a BamHI-BglII fragment containing the MS2 loop sequence was excised from pSL1 180 and ligated to the BamHI site of pUG36w/oGFP, followed by blunt-ending and ligation to the SmaI site to yield pUG36MS2L. Next, the ATP2 or OXA1 ORF was amplified by PCR using primers bearing the SpeI restriction site and inserted into the SpeI site of the polylinker of pUG36MS2L to yield plasmid pATP2MS2L or pOXA1MS2L. The ATP2 or OXA1 3' UTRs (500 bp) were amplified by PCR using primers bearing Xhol restriction sites and cloned into the XhoI site of either pATP2MS2L or pOXA1MS2L to yield pATP2MS2L $+3^{\prime} \mathrm{UTR}$ and pOXA1MS2L $+3^{\prime} \mathrm{UTR}$, respectively. Plasmids pMS2LATP2 + 3'UTR-ATGmut and pMS2LOXA1 + 3'UTR-ATGmut, which express MS2L-tagged full-length ATP2 or OXA1 mRNAs bearing a mutation in its initial ATG, respectively, were created using the $P f u$ Taq polymerase, specific mutagenic primers, and plasmids pATP2MS2L +3 'UTR or pOXA1MS2L+3'UTR. A plasmid, pMS2LATP2-ATGmut, expressing
MS2L-tagged ATP2 mRNA lacking its 3' UTR but bearing a mutation in its initial ATG, was created using the $P f u$ Taq polymerase, specific mutagenic primers, and plasmid pATP2MS2L. All constructs were verified by DNA sequencing.

To evaluate the role of Tom 20 in mMP localization, TOM20 was deleted in various $M S 2 L$-integrated strains using a TOM20 deletion construct. This construct, pYM45Tom20Del, was created by amplifying a 500-bp fragment beginning from the $5^{\prime}$ end of the TOM20 promoter by PCR and subcloning it into the Sall site of pYM45 (a vector bearing the kanMX selection marker) directly 5' of kanMX to generate pYM45Tom20Prom. Next, a PCR-amplified 500-bp fragment containing the TOM20 3' UTR (5' to the stop codon) was subcloned into the SpeI site of pYM45Tom20Prom directly $3^{\prime}$ to $k a n M X$ to yield pYM45Tom20Del. The resulting plasmid was then cut with NotI and transformed into the MS $2 L$ integrated strains. The strains were then grown on solid synthetic medium containing kanamycin $(0.02 \%)$ for $4 \mathrm{~d}$ at $26^{\circ} \mathrm{C}$. To confirm integration, genomic DNA was extracted from single colonies and verified by PCR amplification, using a forward oligonucleotide complementary to the TOM 20 promoter and reverse oligonucleotide complementary to the kanMX marker.

To assess the role of Puf3 in mMP localization, puf $3 \Delta$ strains were created by first amplifying the kanMX selection marker in plasmid pYM45 by PCR using a forward oligonucleotide complementary to the $3^{\prime}$ end of the PUF3 promoter and $5^{\prime}$ end of kanMX, and a reverse oligonucleotide complementary to the $3^{\prime}$ end of kanMX and 3' UTR of PUF3. The PCR product was transformed into the $M S 2 L$-integrated strains and grown on solid synthetic medium containing kanamycin $(0.02 \%)$ for $4 \mathrm{~d}$ at $26^{\circ} \mathrm{C}$. To confirm integration, genomic DNA was extracted from single colonies and verified by PCR amplification using a forward oligonucleotide complementary to the PUF3 promoter and reverse oligonucleotide complementary to the kanMX marker.

\section{Genomic integration of the MS2 aptamer sequence}

For each gene to be tagged with the MS2 aptamer, a forward oligonucleotide complementary to the $3^{\prime}$ end of the coding region (overlapping by $\sim 40$ bp including stop codon) and $5^{\prime}$ end of the loxP::Sphis5+::loxP::MS2L cassette was used, along with a reverse oligonucleotide complementary to the $3^{\prime}$ UTR (by $\sim 40$ bp) and $3^{\prime}$ end of the loxP::Sphis5+::loxP ::MS2L cassette, in the PCR reaction with pLOXHIS5MS2L as the template (Haim et al. 2007; HaimVilmovsky and Gerst 2009). PCR products of the correct size were transformed into yeast and grown on plates containing SC medium lacking histidine for $3-5 \mathrm{~d}$ in $26^{\circ} \mathrm{C}$. To confirm integration, genomic DNA was extracted from single colonies and PCR amplification, using a forward primer complementary to the coding region and reverse primer complementary to the loxP::Sphis5+:: loxP::MS2L cassette and 3 ' UTR, was performed. PCR products were sized on agarose gels and sequenced for verification. Yeast bearing correct loxP::Sphis5+::loxP::MS2L integrations were transformed with plasmid pSH47 and grown on SC medium lacking histidine and uracil. Cre recombinase expression was induced by growing transformed cells in SC medium containing $3 \%$ galactose and lacking uracil for $16 \mathrm{~h}$ in $26^{\circ} \mathrm{C}$. Cells were then diluted, plated, and grown on SC medium lacking uracil; and replica-plated to determine the presence or absence of the Sphis5+ auxotrophic marker. Yeast bearing the loxP::MS2L integration ( $\sim 790$ bp including loxP and MS2L) were verified by PCR 
amplification (using oligonucleotides complementary to the coding region and 3' UTR, respectively) and DNA sequencing. MS2-CP binding sites (MS2L) were integrated into wild-type yeast between the coding region and $3^{\prime}$ UTR of the genes.

\section{Quantification of mRNA copy number in fluorescent $A T P 2_{\text {INT }}$ mRNA granules}

To quantify the number of ATP2 mRNA molecules in the MS2CP-GFP(x3)-labeled granules seen in $A T P 2_{I N T}$ cells, we used an endogenous GFP fluorescence standard (e.g., GFP-LacI) that can be detected in the nuclei of yeast bearing 128 copies of the lac operator integrated into the genome, as described previously in Haim et al. (2007) and Haim-Vilmovsky and Gerst (2009).

\section{SUPPLEMENTAL MATERIAL}

Supplemental material is available for this article.

\section{ACKNOWLEDGMENTS}

We thank Kerry Bloom, Susan Michaelis, and Robert Singer for reagents. This study was supported by grants to J.E.G. from the Minerva Foundation, Germany, the Y. Leon Benoziyo Institute for Molecular Medicine, and the Center for Scientific Excellence, Weizmann Institute, Israel. J.E.G. holds the Besen-Brender Chair in Microbiology and Parasitology, Weizmann Institute.

Received January 7, 2011; accepted May 20, 2011.

\section{REFERENCES}

Aronov S, Gelin-Licht R, Zipor G, Haim L, Safran E, Gerst JE. 2007. mRNAs encoding polarity and exocytosis factors are cotransported with the cortical endoplasmic reticulum to the incipient bud in Saccharomyces cerevisiae. Mol Cell Biol 27: 3441-3455.

Calero M, Collins RN. 2002. Saccharomyces cerevisiae Pra1p/Yip3p interacts with Yiplp and Rab proteins. Biochem Biophys Res Commun 290: 676-681.

Corral-Debrinski M, Blugeon C, Jacq C. 2000. In yeast, the $3^{\prime}$ untranslated region or the presequence of ATM1 is required for the exclusive localization of its mRNA to the vicinity of mitochondria. Mol Cell Biol 20: 7881-7892.

Dekker PJ, Ryan MT, Brix J, Muller H, Honlinger A, Pfanner N. 1998. Preprotein translocase of the outer mitochondrial membrane: Molecular dissection and assembly of the general import pore complex. Mol Cell Biol 18: 6515-6524.

Dilcher M, Veith B, Chidambaram S, Hartmann E, Schmitt HD, Fischer von Mollard G. 2003. Uselp is a yeast SNARE protein required for retrograde traffic to the ER. EMBO J 22: 36643674.

Dingwall C, Laskey RA. 1991. Nuclear targeting sequences-a consensus? Trends Biochem Sci 16: 478-481.

Eliyahu E, Pnueli L, Melamed D, Scherrer T, Gerber AP, Pines O, Rapaport D, Arava Y. 2010. Tom20 mediates localization of mRNAs to mitochondria in a translation-dependent manner. Mol Cell Biol 30: 284-294.

Garcia M, Darzacq X, Delaveau T, Jourdren L, Singer RH, Jacq C. 2007. Mitochondria-associated yeast mRNAs and the biogenesis of molecular complexes. Mol Biol Cell 18: 362-368.

Garcia M, Delaveau T, Goussard S, Jacq C. 2010. Mitochondrial presequence and open reading frame mediate asymmetric localization of messenger RNA. EMBO Rep 11: 285-291.
Geissler A, Krimmer T, Bomer U, Guiard B, Rassow J, Pfanner N. 2000. Membrane potential-driven protein import into mitochondria. The sorting sequence of cytochrome $b_{2}$ modulates the $\Delta \Psi$-dependence of translocation of the matrix-targeting sequence. Mol Biol Cell 11: 3977-3991.

Geng J, Shin ME, Gilbert PM, Collins RN, Burd CG. 2005. Saccharomyces cerevisiae Rab-GDI displacement factor ortholog Yip3p forms distinct complexes with the Yptl Rab GTPase and the reticulon Rtn1p. Eukaryot Cell 4: 1166-1174.

Gerber AP, Herschlag D, Brown PO. 2004. Extensive association of functionally and cytotopically related mRNAs with Puf family RNA-binding proteins in yeast. PLoS Biol 2: e79. doi: 10.1371/ journal.pbio.0020079.

Gerst JE. 2008. Message on the web: mRNA and ER co-trafficking. Trends Cell Biol 18: 68-76.

Gonsalvez GB, Urbinati CR, Long RM. 2005. RNA localization in yeast: moving towards a mechanism. Biol Cell 97: 75-86.

Haim L, Zipor G, Aronov S, Gerst JE. 2007. A genomic integration method to visualize localization of endogenous mRNAs in living yeast. Nat Methods 4: 409-412.

Haim-Vilmovsky L, Gerst JE. 2009. m-TAG: a PCR-based genomic integration method to visualize the localization of specific endogenous mRNAs in vivo in yeast. Nat Protoc 4: 1274-1284.

Harmey MA, Hallermayer G, Korb H, Neupert W. 1977. Transport of cytoplasmically synthesized proteins into the mitochondria in a cell free system from Neurospora crassa. Eur J Biochem 81: 533-544.

Herrmann JM, Bonnefoy N. 2004. Protein export across the inner membrane of mitochondria: The nature of translocated domains determines the dependence on the Oxal translocase. J Biol Chem 279: 2507-2512.

Hoepfner D, Schildknegt D, Braakman I, Philippsen P, Tabak HF. 2005. Contribution of the endoplasmic reticulum to peroxisome formation. Cell 122: 85-95.

Honlinger A, Bomer U, Alconada A, Eckerskorn C, Lottspeich F, Dietmeier K, Pfanner N. 1996. Tom7 modulates the dynamics of the mitochondrial outer membrane translocase and plays a pathway-related role in protein import. EMBO J 15: 21252137.

Karniely S, Pines O. 2005. Single translation-dual destination: mechanisms of dual protein targeting in eukaryotes. EMBO Rep 6: $420-425$.

Kellems RE, Allison VF, Butow RA. 1974. Cytoplasmic type $80 \mathrm{~S}$ ribosomes associated with yeast mitochondria. II. Evidence for the association of cytoplasmic ribosomes with the outer mitochondrial membrane in situ. J Biol Chem 249: 3297-3303.

Kellems RE, Allison VF, Butow RA. 1975. Cytoplasmic type 80S ribosomes associated with yeast mitochondria. IV. Attachment of ribosomes to the outer membrane of isolated mitochondria. J Cell Biol 65: 1-14.

Kornmann B, Currie E, Collins SR, Schuldiner M, Nunnari J, Weissman JS, Walter P. 2009. An ER-mitochondria tethering complex revealed by a synthetic biology screen. Science 325: 477481.

Kraut-Cohen J, Gerst JE. 2010. Addressing mRNAs to the ER: cis sequences act up! Trends Biochem Sci 35: 459-469.

Kumar A, Agarwal S, Heyman JA, Matson S, Heidtman M, Piccirillo S, Umansky L, Drawid A, Jansen R, Liu Y, et al. 2002. Subcellular localization of the yeast proteome. Genes Dev 16: 707-719.

Lillie SH, Brown SS. 1994. Immunofluorescence localization of the unconventional myosin, Myo2p, and the putative kinesin-related protein, Smylp, to the same regions of polarized growth in Saccharomyces cerevisiae. J Cell Biol 125: 825-842.

Lithgow T, Cuezva JM, Silver PA. 1997. Highways for protein delivery to the mitochondria. Trends Biochem Sci 22: 110-113.

Liu JM, Liu DR. 2007. Discovery of a mRNA mitochondrial localization element in Saccharomyces cerevisiae by nonhomologous random recombination and in vivo selection. Nucleic Acids Res 35: 6750-6761. 
Maccecchini ML, Rudin Y, Schatz G. 1979. Transport of proteins across the mitochondrial outer membrane. A precursor form of the cytoplasmically made intermembrane enzyme cytochrome $c$ peroxidase. J Biol Chem 254: 7468-7471.

MacKenzie JA, Payne RM. 2007. Mitochondrial protein import and human health and disease. Biochim Biophys Acta 1772: 509-523.

Marc P, Margeot A, Devaux F, Blugeon C, Corral-Debrinski M, Jacq C. 2002. Genome-wide analysis of mRNAs targeted to yeast mitochondria. EMBO Rep 3: 159-164.

Margeot A, Blugeon C, Sylvestre J, Vialette S, Jacq C, Corral-Debrinski M. 2002. In Saccharomyces cerevisiae, ATP2 mRNA sorting to the vicinity of mitochondria is essential for respiratory function. EMBO J 21: 6893-6904.

Margeot A, Garcia M, Wang W, Tetaud E, di Rago JP, Jacq C. 2005. Why are many mRNAs translated to the vicinity of mitochondria: a role in protein complex assembly? Gene 354: 64-71.

Martin J, Mahlke K, Pfanner N. 1991. Role of an energized inner membrane in mitochondrial protein import. $\Delta \psi$ drives the movement of presequences. J Biol Chem 266: 18051-18057.

Moczko M, Dietmeier K, Sollner T, Segui B, Steger HF, Neupert W, Pfanner N. 1992. Identification of the mitochondrial receptor complex in Saccharomyces cerevisiae. FEBS Lett 310: 265-268.

Muto T, Obita T, Abe Y, Shodai T, Endo T, Kohda D. 2001. NMR identification of the Tom 20 binding segment in mitochondrial presequences. J Mol Biol 306: 137-143.

Neupert W, Herrmann JM. 2007. Translocation of proteins into mitochondria. Annu Rev Biochem 76: 723-749.

Neuspiel M, Schauss AC, Braschi E, Zunino R, Rippstein P, Rachubinski RA, Andrade-Navarro MA, McBride HM. 2008. Cargo-selected transport from the mitochondria to peroxisomes is mediated by vesicular carriers. Curr Biol 18: 102-108.

Otte S, Belden WJ, Heidtman M, Liu J, Jensen ON, Barlowe C. 2001. Erv4lp and Erv46p: new components of COPII vesicles involved in transport between the ER and Golgi complex. J Cell Biol 152: 503-518.

Pfanner N, Wiedemann N, Meisinger C, Lithgow T. 2004. Assembling the mitochondrial outer membrane. Nat Struct Mol Biol 11: 1044-1048.

Prinz WA, Grzyb L, Veenhuis M, Kahana JA, Silver PA, Rapoport TA. 2000. Mutants affecting the structure of the cortical endoplasmic reticulum in Saccharomyces cerevisiae. J Cell Biol 150: 461-474.

Prokisch H, Scharfe C, Camp DG II, Xiao W, David L, Andreoli C, Monroe ME, Moore RJ, Gritsenko MA, Kozany C, et al. 2004. Integrative analysis of the mitochondrial proteome in yeast. PLoS Biol 2: e160. doi: 10.1371/journal.pbio.0020160.

Regev-Rudzki N, Yogev O, Pines O. 2008. The mitochondrial targeting sequence tilts the balance between mitochondrial and cytosolic dual localization. J Cell Sci 121: 2423-2431.
Saint-Georges Y, Garcia M, Delaveau T, Jourdren L, Le Crom S, Lemoine S, Tanty V, Devaux F, Jacq C. 2008. Yeast mitochondrial biogenesis: a role for the PUF RNA-binding protein Puf3p in mRNA localization. PLOS ONE 3: e2293. doi: 10.1371/journal. pone.0002293.

Schuldiner M, Metz J, Schmid V, Denic V, Rakwalska M, Schmitt HD, Schwappach B, Weissman JS. 2008. The GET complex mediates insertion of tail-anchored proteins into the ER membrane. Cell 134: 634-645.

Schulke N, Sepuri NB, Pain D. 1997. In vivo zippering of inner and outer mitochondrial membranes by a stable translocation intermediate. Proc Natl Acad Sci 94: 7314-7319.

Schwartz TU. 2007. Origins and evolution of cotranslational transport to the ER. Adv Exp Med Biol 607: 52-60.

Sickmann A, Reinders J, Wagner Y, Joppich C, Zahedi R, Meyer HE, Schonfisch B, Perschil I, Chacinska A, Guiard B, et al. 2003. The proteome of Saccharomyces cerevisiae mitochondria. Proc Natl Acad Sci 100: 13207-13212.

Slobodin B, Gerst JE. 2010. A novel mRNA affinity purification technique for the identification of interacting proteins and transcripts in ribonucleoprotein complexes. RNA 16: 22772290.

Sylvestre J, Margeot A, Jacq C, Dujardin G, Corral-Debrinski M. 2003. The role of the $3^{\prime}$ untranslated region in mRNA sorting to the vicinity of mitochondria is conserved from yeast to human cells. Mol Biol Cell 14: 3848-3856.

Szyrach G, Ott M, Bonnefoy N, Neupert W, Herrmann JM. 2003. Ribosome binding to the Oxal complex facilitates co-translational protein insertion in mitochondria. EMBO J 22: 6448-6457.

Tabak HF, van der Zand A, Braakman I. 2008. Peroxisomes: minted by the ER. Curr Opin Cell Biol 20: 393-400.

Truscott KN, Voos W, Frazier AE, Lind M, Li Y, Geissler A, Dudek J, Muller H, Sickmann A, Meyer HE, et al. 2003. A J-protein is an essential subunit of the presequence translocase-associated protein import motor of mitochondria. J Cell Biol 163: 707-713.

Wienhues U, Becker K, Schleyer M, Guiard B, Tropschug M, Horwich AL, Pfanner N, Neupert W. 1991. Protein folding causes an arrest of preprotein translocation into mitochondria in vivo. J Cell Biol 115: 1601-1609.

Wu Y, Sha B. 2006. Crystal structure of yeast mitochondrial outer membrane translocon member Tom70p. Nat Struct Mol Biol 13: 589-593.

Zipor G, Haim-Vilmovsky L, Gelin-Licht R, Gadir N, Brocard C, Gerst JE. 2009. Localization of mRNAs coding for peroxisomal proteins in the yeast, Saccharomyces cerevisiae. Proc Natl Acad Sci 106: $19848-19853$. 

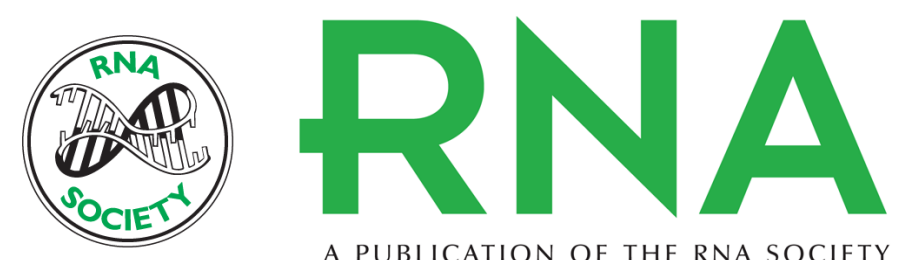

A PUBLICATION OF THE RNA SOCIETY

\section{Localization of mRNAs coding for mitochondrial proteins in the yeast Saccharomyces cerevisiae}

Noga Gadir, Liora Haim-Vilmovsky, Judith Kraut-Cohen, et al.

RNA 2011 17: 1551-1565 originally published online June 24, 2011

Access the most recent version at doi:10.1261/rna.2621111

\section{Supplemental http://rnajournal.cshlp.org/content/suppl/2011/06/13/rna.2621111.DC1 \\ Material}

References This article cites 57 articles, 30 of which can be accessed free at: http://rnajournal.cshlp.org/content/17/8/1551.full.html\#ref-list-1

\section{License}

Email Alerting Receive free email alerts when new articles cite this article - sign up in the box at the Service top right corner of the article or click here. 